\title{
Promoting Sociability
}

\section{Staff Perceptions of Music Therapy as a way to Enhance Social Skills.}

A project presented in partial fulfilment of the requirements for the degree of

\author{
Master of Music
}

In

Music Therapy

New Zealand School of Music, Wellington, New Zealand

Emma Jane Boniface

2009 


\begin{abstract}
This thesis is the result of working with nine students and one teacher aide in group music therapy in special education. Through opportunities to learn about music and sound, the students were invited to use descriptive language to express emotions and thoughts about their music therapy experience. This research used a qualitative research design, where the purpose was to learn about the perceptions that staff may have of music therapy and to highlight how music therapy can promote sociability in an educative setting. The data collected mainly through research journal entries and two interviews (as well as material from a discussion group) offer evidence about how improvisational group music therapy can help create a positive social environment in the classroom and complement socialisation goals in education.
\end{abstract}




\section{Acknowledgements}

This research project could not have been completed without all the support I have had during my placement and over the last two years of my master's study in Wellington. Thank you to all the students and staff that helped to make my time as part of the group so special, and all the fantastic people that showed an interest in what I was setting out to achieve.

Specifically, I would like to thank Sarah Hoskyns for her invaluable guidance during my studies, Judy Cooper for looking out for me in supervision, and Fiona Clark for her help with editing.

Finally I would like to dedicate this work to my family and to my loved ones. Thank you for putting up with me on this journey and enabling me to pick up where I left off.

This project is written in loving memory of Carol Boniface.

This project has been reviewed and approved by the Massey University Human Ethics Committee: Southern A, Application 08/27. 


\section{Table of Contents}

Abstract i

Acknowledgements ii

Introduction 1

Review of Related Literature 9

Method 23

Findings $\quad 35$

Discussion $\quad 52$

Summary $\quad 59$

References $\quad 61$

Appendices 64 


\section{Introduction}

In my journey towards becoming a New Zealand registered music therapist I had the opportunity to spend a year researching and working in special education. Since beginning my studies in, and working towards my Master of Music Therapy I have had an interest in the role of music therapy in special education. In this research, I have had a specific interest in the attitudes that adolescents have towards music therapy and working as part of a group.

The promotion of sociability through education is an important factor in the classroom. The development of peer relationships can be crucial to the individual growth of the student, especially during the period of adolescence. This is particularly true of adolescents with special needs as they can often feel isolated from other people in their age group due to challenges with communication. The main aims of music therapy in this setting (and particularly with regard to this research) are to increase meaningful conversation, develop creative thought processes, encourage participation in a social atmosphere, and create an environment where students can feel free to explore their own musicality.

Baron, Riddell, and Wilson (1999) suggest adolescence is a period where the young person is shifting from more 'concrete operations' to 'formal operations' (p.484). This shift marks the transition from adolescence to adulthood. This is presented in the study of developmental psychology, and Baron et al. cite the work of Erikson (1968) as inspiration for their study. Adolescence is said to be the time where identity is formed, and by the time adulthood is met, the underlying moral standard of the individual has been acquired. The hope or 
assumption is that this identity is a stable one. In the field of study of people with disabilities, Baron et al writes that in the last twenty years people with disabilities have been considered to be pathfinders. This means there are more opportunities to stay on at school, and delay the process of joining the workforce. This in turn delays the process of adulthood, and provides the opportunity for further learning and, in accordance with the field of developmental psychology, the strengthening of identity.

As well as providing the opportunity for students to develop a sense of security in shared music therapy sessions, Wheeler, Shultis, and Polen (2005) define group music therapy as being effective for the goals of the client due to the safety and support that a group can provide individual members. Students of a similar developmental stage (as in a school environment) can provide the same sorts of 'challenges' and the levels of functioning of each student can be similar. This provides consistency for the music therapist in which to work.

This research has involved a qualitative exploratory approach, which involved several forms of data collection. The researcher has used background material which was gathered initially from three music therapy sessions, and journals collected from these sessions. The data collection process began with a videoed discussion group of students and staff. The recruited teacher aide was then interviewed immediately after the discussion group and invited to discuss her perceptions of the students in that group setting and the three music therapy sessions we had previously held. The students' teacher was interviewed at a later date to provide another professional perspective of the students in the discussion group. This data was supplemented by my own ongoing research journal, which supported my personal reflection. 
The students were selected members of a senior support class at the Learning Support Centre of a mainstream High School in New Zealand, where group music therapy had been conducted once weekly. A teacher aide was also invited to join this group and take part in music making with the students in order both to support them, and to assist with data gathering for the research. The students took part in three closed group music therapy sessions and one video recorded discussion group. The teacher aide also participated in the same sessions, and concluded with an interview.

This research also came about through an interest in the function of groups to promote sociability, and the possibility that music therapy groups may affect the students in a positive way. The music therapy goals mirror or complement the educational providers' goals set by the students' teachers. I was aware that socialisation was an important goal at the LSC, and encouraging the students to interact in a positive social atmosphere with their peers and other members of their community such as family, friends, and general members of the public was an overall goal.

The following is a clinical introduction to the placement, which is followed by a review of literature, is presented in sub-sections.

After some time at my placement I became interested in the views that staff and student participants had on taking part in a music therapy group. I recognised that I was interested in seeing whether there were any changes in the social atmosphere of the classroom as a result of music therapy, as well as endeavouring to learn and represent the opinions that the group members have about the music group. 
Bunnell (2007) provides an explanation of the structure of the group. She explains that when it is possible the size and the structure of the group should be carefully planned. The abilities of the members of the group, the needs of the participants, the availability of help, and the regularity of the sessions are all things that should be taken into account when planning sessions. Other things that cannot be planned but should be catered for are unexpected mood changes, absences, and providing a stable core in the group so that stability is achieved.

As I have mentioned in the introduction to this project, my research aims were to promote sociability in group music therapy and present staff and students' about the process. As well as these research aims, my clinical aims were to increase meaningful conversation, develop creative thought processes, encourage participation in a social atmosphere, and create an environment where students would feel free to explore their own musicality. I wanted to provide an appropriate setting where students would feel safe and secure in the group with the possibility of encouraging the social behaviours between members of the group. Clair (1989) writes that one of the pioneers of music therapy, and a keen musician, Willem van de Wall (1887-1953) believed that therapies must result in a balanced, reintegrated personality and promote social adjustment. In the review of his life and his work, the authors explain that van de Wall believed that music to be "extremely useful" (Clair, 1989, p.169) in the process of promoting social adjustment.

Groups have been formed in settings such as social work. Originally from a national conference paper, Newsetter (1935), cited in Malekoff (1997), discusses the group and the processes that have been adapted in this study. 
Group work may be defined as an educational process emphasizing (1) the development and social adjustments of an individual through voluntary group association; and (2) the use of this association as a means of furthering other socially desirable ends. It is concerned therefore with both individual growth and social results. Moreover, it is the combined and consistent pursuit of both these objectives, not merely one of them, that distinguishes group work as a process. (291)

When I learned that I would be working in the field of special education I was enthusiastic about my year of clinical placement and beginning to conduct my research in the educational field in New Zealand. For me, it was an ideal combination - linking my training and experience in contemporary music (valuable study when working with adolescents), and my general interest in special education. I was very interested in working in the multidisciplinary context described previously, where I would liaise with teachers of the clients I was seeing in music therapy, and discuss appropriate interventions and techniques for reaching students. This multidisciplinary model was cited in Twyford and Watson (2008) as one of the models both identified and defined by Krout (2004) and Wheeler (2003).

My placement was at a New Zealand Learning Support Centre (LSC), which was part of the mainstream high school attended by over 1000 students. The LSC was a separate centre for students with varying needs, where they would receive the support they needed from a group of teachers and teacher aides. The LSC consisted of approximately 35 students, all with a range of varying disabilities, and ages ranging from 13-21. There were approximately 15 staff employed at the LSC, and these staff consisted of teachers, administrators and teacher aides.

Half way through the year, the students and staff of the LSC were transferred temporarily off site so that repairs could be made to their classrooms. This saw us being taken to a small, 
empty school, around 6 kilometres from the school site. This change meant some readjustments for everyone, and challenges to make sure the students were comfortable and settled in their new environment. This change meant that the inclusive educational practice (such as mainstreaming, attending school assembly, attending form class) was removed, and the students were left solely to interact with their peers and the teachers at the LSC.

Over the course of my placement I had a lot of discussions with teachers, parents, and students about the goals of my clinical practice, and how that work within the LSC would be reflected in my research. While working in special education I wanted to see if music therapy could compliment the LSC, and the goals that are implemented by the students' educators. Generally in conversations, I found that people appreciated the perspective that these therapies had to offer, whether music therapy, speech language therapy, or occupational therapy. I believe that many education providers may be willing to try several avenues of work to see what will have a positive impact on individual students. Therapy is used for the benefit for the client, and it is the responsibility of the therapist to work to be efficient, effective and safe. From my own personal experience of being a student music therapist (SMT) I have had the opportunity to select most of my own clientele, and the clients selected have generally had positive reactions to music. I am aware that the outcomes depend on the individual client, and that not all therapies always have positive outcomes.

As the students continued to respond and react positively to music therapy, I felt highly motivated to conduct research. The outcomes of the research were mutually beneficial, as the students had an opportunity to take part in something they generally enjoy, and I had the chance to work with students in a musical setting. 
In their project for behaviour management Andrews and Clark (2005) describe how a 'wraparound' approach suitable for in working with students with behavioural and emotional difficulties. These wraparound approaches consist of individual plans and positive reinforcement. In the music therapy group I facilitated I adopted and utilised these plans. I continually emphasised positive reinforcement, and made sure I was aware of the individual needs of the students that took part in the group.

As well as providing an opportunity to learn about music and sound, the students were invited to use descriptive language to express emotions and thoughts. Music therapy in special education can be understood as being complementary to the education of the student and can offer different avenues of learning, and alternative ways of thinking. In this project, I have delivered group music therapy sessions with students as another means to encourage and increase positive social interaction between the students belonging to that peer group.

All of the material that has been presented in other studies conducted by music therapists as well as other professionals helps the reader, as well as the researcher to understand the need to create goals of positive socialisation for the benefit of the student in the educational system. An Individualised Education Plan (IEP) promotes an understanding of students' individual needs and goals. Whilst reading IEP's it is apparent that socialisation is very important for future development and taking part in society. Kim, Wigram, and Gold (2008) cite several authors to strengthen the argument that "music offers a means of selfexpression, communication and interaction that can be more easily assimilated by the children than some other medium" (Kim et al. 2008, p.1758) 


\section{$\underline{\text { Research Questions }}$}

The first research question came about through my interest in what staff and children thought about the contribution of Music Therapy to socialisation in the classroom, and their opinions about taking part in a music therapy group. To put it simply, what did they think about music therapy, and what did they think about spending time in music together ${ }^{1}$

The second question aimed to identify appropriate therapeutic activities that students and teachers (and I as therapist) considered helpful in promoting sociability in special education and to begin to recommend resources that could be used to stimulate and encourage group work and group goals in the classroom. Therefore, what activities were perceived as helpful in the promotion of sociability?

\footnotetext{
${ }^{1}$ The reader is referred to the note in the methodology section on page 32 for details about how the research was revised for the final writing of the thesis. 


\section{Review of Related Literature}

The purpose of this literature review is to place my study within a tradition of other enquiry. As Dileo (in Wheeler, 2005) explains, the literature review functions in order to lay out the already existing knowledge on a specific topic. Previously published material is presented and the current study uses this literature to define the current topic, or to show the gaps that the study may fill. I have used the literature in this study to gain knowledge from other authors and researchers that have completed studies that I consider related to my own.

As I have stated in the previous introductory sections of this project, there have been several reasons why I have been motivated to carry out this research. The review of related literature furthered my motivation. In conducting my literature search, I found that many gaps appeared in the topics that I was searching for. I found that there were many texts that addressed part of my topic, but not the entirety of my project. Specifically, my project revolves around the following fields: special education, adolescents, music therapy, group music therapy, improvisation, client-centred music therapy, and sociability. These fields were initially used as criteria for looking for research material and to provide a background to my work. In these searches I have had the goal of finding out information specifically about working in music therapy groups with adolescents in special education. I have looked for further literature within this topic specifically material on improvisational group music therapy with a focus of encouraging socialisation within the group. I looked for this material in order to strengthen my work, and to see if there are any studies on how music therapy provides a sociable environment. 
This review of literature draws on related studies in a number of key areas. These are music therapy in special education (emphasising adolescence), music therapy and group work (in particular group improvisation), socialisation, and aspects of special education in New Zealand. I have looked for articles, books and journals that offer insight into my related working environment, and to help the reader to understand the context in which my work resides. I also attempted to find the gaps in the research in order to justify my own work.

This literature review has been divided up into themes that the individual articles are concerned with. The first section contains articles that address improvisation. The second theme looks at live music vs. pre-recorded music. The third theme looks at literature on social skills in special needs and the fourth provides information on identity. The next section follows with a presentation of literature about group music therapy, and then the function of the group. Finally, research in relationships is discussed.

\section{Music therapy and Special Education}

Rickson and McFerran's (2007) article Music Therapy in Special Education provides an overview of research that has been conducted in music therapy. It "outlines the historical precedent for an increasing qualitative emphasis and describes the current knowledge base generated through the literature on the topic of music therapy and special education." (Rickson, et al. 2007, p.1) This article looks at the need for new research in this field, and with propositions for future studies. This article explains the need for qualitative research to be carried out in the field of education and music therapy.

Music Therapy and Improvisation 
Kim, Wigram and Gold (2008) have completed a study in improvisational music therapy on pre-school children with Autism. The study compared the effectiveness of music therapy compared with play. They found that "The overall results indicated that improvisational music therapy was more effective at facilitating joint attention behaviours and non-verbal social communication skills in children than play." (Kim et al. 2008, p.1758) This quantitative study involved thirteen boys and two girls aged between 3 and 5 with a diagnosis of autism, in a Korean hospital setting. There, each of the participants had 12 weekly 30 minute individual improvisational music therapy sessions. The control conditions were 12 weekly 30 minute play sessions with toys. The comparative sessions were run by a team of both music therapists and play therapists, and the sessions were carried out in a manner that aimed to avoid person familiarity. A manual was also developed to ensure consistency through all therapists that were working in the study. As a means of measuring before, during, and after effects, The Pervasive Developmental Disorder Behaviour Inventory-C (PDDBI; as cited in Cohen and Subhalter, 1999), and the Early Social Communication Scales (ESCS as cited in Mundy, Delgado, Block, Venezia, Hogan and Seibert, 2003) were applied. The findings of the ANOVA show that interaction of time and group was significant $(p=0.01)$ indicating that music therapy was considerably more effective than play sessions in addressing joint attention skills. Although this study differs in many ways to my research it was interesting to note the general effectiveness of improvisational music therapy and its impact on social skills for children with special needs.

Another example of research involving improvisation is found in a study carried out by Erkkila (2004). Erkkila cites Rolsvjord (2004) as pointing out, too, that in other work music is described as being in opposition to verbal language. He links back to Helen Bonny, who has 
stated that music is the language of immediacy. Bonny considers music a perfect medium for improvisation, as it is capable of being completely free and open-ended, and yet highly organised and structured. Erkkila describes improvisation as being an act between client and music therapist where sensory and motor affects or semiotics form the basic constructs of meaning. This act consists of expression which is a kind of emotional language.

Looking at the music, meaning and relationship (further along in chapter 7) Pavlicevic (1997) studies the meaning of relationship and the creation of a relationship through music. In an example, the music therapist uses improvisation to support the client, with the goal of creating music together. Pavlicevic writes that "music therapy improvisation appeals not only to the symptoms but to the whole person, including those aspects that are not 'ill', and including those aspects of the client that have only an obtuse relationship to the 'illness'."(Pavlicevic, 1997, p.93) My research, which has focused on the music group and the opinions of that group, has never been specifically about the diagnosis of individual students, or with making music with that aspect of their persona in mind. The relationships between students and teachers have been created through the use of improvisational music therapy in order to increase the socialisation of the group.

McFerran and Wigram (2002) completed a review of current practice in group music therapy improvisations. The purpose of this article is to display the findings of music therapists with a history of working within group music therapy using improvisational methods. Findings from interviews provide a framework that draws conclusions about improvisational music therapy in group settings. The material that was found in the interview provides some insight into working with groups in music therapy. It was found that each therapist offers their own personal opinions on group music therapy, and this 
provides diversity in the answers, as well as providing similarities in the therapists practice and theory.

\section{The use of Live Music in Music Therapy}

Standley (1996) used meta-analysis to identify patterns and trends in research in education. (For the purpose of this work, the information on music is reviewed.) In this study it was found that live music was more effective than recorded music, and borrows from other studies in the field of music education and therapy, and in medical and dental treatment. Standley's revised study (1996) reviewed 92 studies and 233 dependent variables, which showed an overall effect size on primary variables due to music of 1.17. Live music (ES=1.13) was more effective than recorded music $(E S=.86)$. Studies using the subjects' preferred music showed an overall effect size of 1.40. This article provides evidence that live music can be used as reinforcement in music and in music therapy settings. In this article, Standley has shown the benefit of finding empirical evidence on the effects of live music versus recorded music in medical settings through comparing literature available to the research team. This meta-analysis provides a theoretical base for quantifying data. This research also allows music therapists to have some confidence in the use of live interventions in clinical practice and in research.

\section{Social Skills in Education}

From an educative point of view Olson, Platt and Dieker (2008) write that sometimes students with special needs can display inappropriate social skills and that this can isolate them from other students. They report only a small amount of standards in social skills are available in education, and they wish to remind the educator that equal emphasis should be 
put on the social aspects of learning alongside other types of intervention strategies (Olson et al. 2008, (p.262). Several identification strategies are listed, and a skill based intervention is included through the citation of Smith (1995). This skill based intervention can be related to music therapy. With the focus of increasing social skills, group therapy plans can be administered to address the skill deficits of students (such as turn taking and sharing activities) in a therapeutic manner. This is to say that social skills are important in education, but can also be worked on by other members of the multidisciplinary team.

\section{$\underline{\text { Identity }}$}

Ruud (1998) focuses on music and identity and asks the question: what does the music we like say about us? What do our peers think it means about who we are as people if music does in fact show our 'true selves' (Ruud, 1998, p.31). The author writes that there are four categories that cover all aspects of music and identity: music and personal space, music and social space, the space of time and place, and transpersonal space. The concept of Identity in this study refers to an individual's particular combination of personal characteristics. These characteristics include name, age, gender and profession. This more public aspect of identity contrasts with the inner, experimental side of self-awareness. In social and personality psychology, identity is sometimes used to describe dimensions within the personality or traits that distinguish people. Identity in the field of education with adolescents is very important. It is crucial that the students are able to develop a sense of identity so that they can be aware of their social standings with other members of their group. Adolescence is typically the time that an individual makes decisions about their identity in order to differentiate or assimilate themselves with other individuals, which can create friendships. Identity is considered by some theorists, such as Erikson (1995) to be 
important developmentally, especially in the stage of adolescence, where the individual is pushed into another age of personal change.

\section{Group Music Therapy}

Potter (2007) has completed action research to facilitate verbal interactions with a group of developmentally delayed adolescents. She found that through working with a small group in music therapy that both musical and social interaction increased over time, and a shift from concrete to descriptive language appeared in the students.

Using group music therapy to help facilitate change within the group can be helpful alongside educational intervention, and through Potters research, she also shows that group music therapy can be helpful in the personal growth of the music therapist.

Borczon (1997) is concerned with music and life in the context of basic relationships. A quote that I found quite interesting and possibly relevant to the group that I run is centred on behaviours.

"The main issue is that life has become complex, at times very difficult, and it is controlled by an underlying theme. In essence, the subject (noun) may have also subjected himself in certain types of behaviour. This type of form in one's life can be very destructive. As he engages in behaviours, which splinters his life, he cannot seem to consciously find the reason for these behaviours or even understand why he engages in them. His therapy is one of truly finding the main theme or subject that fuels the process." (Borczon, 1997, p.14)

With this in mind, I think about the role of the students that were involved in this research. What they experience outside of the group has shaped their personalities and contributed to their behaviours. Now the differentiation between my thought and the extract above is that in my group I did not see all behaviours as being negative. Life certainly is complex for 
the students that I see, but this complexity does not necessarily dictate a negative outcome in therapy. If a client does wish to express themselves, the theme of their expression can be addressed in the provided therapeutic setting. I agree with Borczon when he writes that "Music is a gift. It can be entertaining, relaxing, energizing, sad, soulful, contemplative and creative. Through all these things that IT is, for many IT becomes therapeutic. The special gift of music then, is that one can find his way through the music, with the aid of his guide, to a better place." (Borczon, 1997, p.21) The reading of Borczon was initially helpful in this research by helping me ground my clinical work in order to help construct a potentially beneficial research project.

Pavlicevic's (2003) book explains the strategies for music therapy groups. The aims from the group can be to improve the social atmosphere through sustaining social skills.

She explains that the group can create social bonding and social space. The positive side of music creating a social space can generate social bonding. On the flipside, it can also create social alienation, where the individual is rejected from the group. In other words, the creating of social bonding and creating a social space, by implication excludes some people. So, while making music together can generate a powerful sense of 'belonging', and gives shape, texture, colour to one's personal experience, equally one's experience can be of being excluded from the collective social space, because of cultural/historical familiarity or sensitivities. Even if these moments of social bonding or alienation are fleeting, their "after shocks" (Pavlicevic, 2003, p.68) remain enormously powerful. Rituals are described as being active and formulated within the group. Pavlicevic sites Smalls' (1998) definition of ritual as the way in which we experience our proper relation with patterns which connect the great pattern of the mind. 
In her research Goodman (2007) discusses the lack of material on the critical issue of individual music therapy versus group music therapy. She provides the citations of Nicholls (2002) and Oldfield (2006) who both suggest that the needs of children may be met in group music therapy if they are not being met in individual music therapy. Goodman explains that the "carefully considered rationale for initial individual versus group music therapy placement for the child is nonexistent." (Goodman, 1997, p.77) She brings up the issue of 'fitting in', in regards to the fields of special education and psychiatry. She asks: does the nature of that group function within the two fields? In the work that I have done, I see that the need for socialisation is a major goal in special education.

In a review of Goodman's book McFerran (2008) writes that "Goodman's main thesis in addressing this dilemma seems to be that the group must function to address individual goals rather than generic group therapy goals that would better suit higher functioning clients." (McFerran, 2008, p.96) She discusses that Goodman's main issue in her work has been towards maintaining functionality in the group while addressing the needs of the individual group members.

Tyler (2002) reports on her experience of working in group music therapy with students that have special needs through two vignettes. She hopes to show though this work that group music therapy can function as another therapeutic intervention to complement the work of the teachers. Tyler believes that group music therapy can make a contribution to "individual children's growth, health, communication and relationships with the self and others (Tyler, 2002, p.229)." Although this work is not a research study, it is a presentation of group music therapy in the field of special education. It is another example of music therapists working 
alongside education providers to design a programme using improvisational music therapy to benefit the students.

\section{Function of Groups}

Borczon (1997) explains what he perceives as the criteria for the effective group. His work was developed from Yalom (1975) and by Magden and Shostrom (1974). The journey through group work and the growth of the group members could be evidenced as they engage in the following dimensions. These dimensions are: (1) Catharsis. Group members often ventilate feelings/or experiences, (2) Group as a second family. Group members identify the therapist and/or other members in family roles, (3) Awareness. Group members become more aware of their thoughts, feelings, and or body responses, (4) Group cohesiveness. Group members appear involved in the group, (5) Receiving information. Group members appear to be open to instructions, advice, and suggestions from the therapist, (6) Imitative behaviour. Group members model their behaviour after the therapist, (7) Faith in the process. Group members' behaviour suggests that the group process will work for them, (8) Giving and receiving help. Group members appear to help one another through support and reassurance. (9) Universality. Group members appear to get insight into how other share their ideas, feelings, and behaviour, and finally, (10) Altruism. Group members appear to feel a sense of caring or love for one another.

I see these ten points as important. They are not always present in every group at all times, but they are steps that could be used to help facilitate change, increase group awareness, and from a research perspective be used as a coding mechanism in the collection of data. 
Aigen (1996) refers to the teachings of Nordoff and Robbins (1977) through various texts that have been compiled. A point of reference to me is the 'conceptual framework' and the role of technique in creative music therapy. Aigen mentions that Robbins writes 'techniques that are communicated "must be modified, adapted, even ignored" depending upon the needs of individual children.' (Aigen, 1996, p.10). The point of this way of thinking is that Music Therapy should be personalised, and just because a technique works with one client, does not mean that it will work with another. The preparation that is done for that one client should be focused on what is the best for that client. In my case, the preparation for my client group is not the same as the other groups that I take. The techniques used in the group differ from other groups, as the goals are different, and the clients are indeed different.

\section{$\underline{\text { Research in Relationships }}$}

Amir's dissertation (1992) has come about from the lack of material on the meaningful moments of research. Amir has used inspiration from her music therapy sessions conducted individually and in groups. She talks about the meaningful indicators in these groups that have arisen in their music experiences, and the need for them to be reported. The main research question for Amir's dissertation is how can these meaningful moments between clients and music therapists be described and understood?,

The literature review in this dissertation covers meaningful moments in a number of fields, including music therapy. The work consists of vignettes from various clients, and collecting data from several music therapists. The data is presented in a qualitative study, with the descriptions of meaningful moments depicted in a tally. The researcher concludes that it is 
important to look at the whole person and that "as educators we have to find ways to make sure that students understand themselves intimately and grow psychologically, spiritually and musically." (Amir, 1992, p.202)

Strange's 1987 article talks about the author working in a school for children with severe learning disabilities, his role as music therapist and the expectations of being part of a larger working community. This article talks about the cross-over that can occur when working in this field and that music therapists can be asked to fill a number of other roles in addition to the role of music therapist.

Lewis and Porter (2004) suggest in their article that there is a list of protocol should be established to represent the views of younger people with disabilities. These concerns lie within research aims, ethics, sampling, design and communication. The main argument of their article is that it is important for researchers and service providers to recognise the right of children and to work towards representing young people's views. The authors recognise that the development of communication skills for children with severe learning difficulties has always been paramount in education. In conclusion the authors realised that there were significant challenges due to the over formalising of processes and to not rush the responses of the younger people with disabilities.

\section{Conclusion of Literature Review}

In order to summarise my literature search, I would like to talk about the range of material that is featured above. The articles that were used cover many fields of study-from music therapy to psychology, and many topics - from inclusion to identity. I found that through this broad search I was able to present how my research touches upon many other forms of 
research. It also shows that in the field of music therapy, there is a need for the type of research I have undertaken. Through my own literature searches, I agree that more research studies need to be completed, and that qualitative studies help to inform other clinicians and educators on the value of music therapy in special education.

Reading the featured studies has helped me to realise what my research can provide in the field of music therapy, group work, and special education.

As in the work of Lewis and Potter (2004), this research aimed to focus on the views and representing adequately the opinions of young persons with learning disabilities. As Rickson and McFerran (2004) suggest, more research is needed in the field of music therapy and special education. Potter (2007) argues that group music therapy, while being helpful in the personal growth of the music therapist, also contributes a rich field of enquiry for the music therapy researcher. 


\section{Method}

This section has been broken down into chronological events, showing the process that this research used. First are Selection Process, Participants, and Recruitment. This is followed by Procedures for Data Collection, Analysis, Ethical Consideration, Research Design, Research Journal, Discussion group, and concludes with Interviews. The purpose of this section is to provide an overview on how the research process came about and to bring together all the elements of this study before going on to the method.

\section{Selection Process, Participants, and Recruitment}

The participants were selected from a pool of students in one class that obtained consent from their parents to take part in this study. All students from the senior class of the LSC were invited to take part by their teacher. After arranging with the teacher to read out the information sheet to the students in the senior class (see appendix), I obtained consent to work with nine students for my music therapy research. The informed consent (example of informed consent information sheet, see appendix) came from either their parents if under the age of 18 , or their parents and themselves. The teacher and teacher aide completed similar forms, giving consent in using their interviews and transcripts in this study (also see appendix).

Students whose parents did not give consent for them to take part in the study were still able to take part in group music therapy. The research group was added on to an already established group music therapy timetable. All students enrolled at the Learning Support Centre (LSC) took part in group music therapy throughout the entire year with their classmates. When the recruited students had group music therapy, their classmates were 
with their teachers, taking part in outdoor activities. The Teachers of the class and I worked together to make sure that there were alternative activities for the students that did not partake in that particular music group.

These students and staff members were assigned pseudonyms for the purpose of this study. They are all members of the same senior class at a learning support centre at a northern New Zealand high school. The group consists of nine students, ages $16-18$ years of age. Information about each student was drawn from their diagnosis sheets, IEP forms, and staff and music therapists' observations. Below is a brief description of each student in the group with their assigned pseudonyms in order to protect their identity.

Andrew was 17 years old and had a diagnosis of Autism. He was quiet and withdrawn, and only participated when addressed individually. He loved music, and has worked with other music therapists in individual settings, and has had piano and cello lessons. He enjoyed playing familiar songs repetitively, responded with a smile when someone else joined him, and also showed he had a good ear for music.

Aaron was 17 Years old and had a diagnosis of developmental delay, with features of Autism. He enjoyed music and participated enthusiastically. He had attended individual music therapy sessions throughout the year, and had good guitar skills. He had previously learned some chords on the guitar and was able to play along with some guidance.

William was 17 years old and had a diagnosis of Aspergers Syndrome. He could be quite set in his ways, and at times difficult to manage. He learnt the violin, and regularly had a lesson with an itinerant violin teacher, and was an active and enthusiastic member of music therapy groups. 
Simone was 19 years old. She had echolalia and was described as being a high needs student. She always spoke in single sentences and often appeared disengaged, but was often actively listening.

Karrie was 17 and had a diagnosis of global developmental delay. She was often friendly and enthusiastic. She was noted by her teachers to have a tendency to be controlling, and increasing her flexibility in the classroom was something they wanted to encourage.

Helen was 16 years old. She had a diagnosis of Goldenhar Syndrome. She has difficulty with speech and has several health needs. Helen was an enthusiastic music maker, and often appeared to be fully engaged in music with her peers.

Jackie was 16 years old. She had a diagnosis of severe Dyspraxia. Her speech impairment required her to sometimes use a device to help her type out words when she found it hard to explain what she means to others. She was very good at expressing her emotions, and could sometimes become frustrated when not understood. She was a caring and compliant member of the group, who became open to trying new things in music.

Billy was 16 years old. He had several diagnoses, but (quite possibly) his diagnosis of attention deficit hyperactivity disorder (ADHD) was the most prominent. He sometimes said inappropriate statements and tended to fidget. He was a friendly student who took part in activities when he was motivated to participate.

Gavin was 20 years of age, and was diagnosed as having global developmental delay. He had a good natural rhythm and appeared to enjoy many activities in music. He was energetic and has a dominant and confident personality. He had the tendency to take over in music, but was mostly friendly and encouraging of other students. 
Brigette was an exchange student, who was studying to become a teacher aide. She was placed at the learning support centre (LSC) for several weeks before returning back home to conclude her education. She was the only teacher aide who requested to participate in the project. Upon agreeing to take part, she indicated that she had a lot of interest in music therapy. She was keen to learn some techniques that she could take back home and use in her own field of study and work. She had also been working individually with Helen on educational goals and researching through observation. Brigette was an ideal teacher aide to work with in this project due to her enthusiasm and the good rapport she had with the students.

The Teacher contributed to this project firstly by approaching the students and their parents about the music therapy group and the research. The Teacher then viewed the material from the discussion group video, and took part in an interview regarding the material in the video. The Teacher offered another perspective of the way that the students reacted to music therapy. He also provided a professional perspective that was removed from the clinical side of the music therapy group, and was able to relate to the project from an educative standpoint.

As well as facilitating music therapy sessions, I was counted as a member of the music therapy group by the staff and the students. I considered myself to be a clinician who would present research about the students in group music therapy. At the time of working on this project, I was 27 years old, from New Zealand, with a background in contemporary music and performance. This was the second year of my studies in music therapy, working solely (and with much interest) in the field of special education. As a student, music therapy gave me the opportunity to work in the past two years with adolescents, primary school 
students, and the elderly. In my research year I worked entirely with adolescents in the special education setting.

As well as using the data that the teacher aide supplied at the conclusion of the discussion group, I also asked the teacher of the students that had taken part in the project to supply some feedback about the video recording. The purpose for this was to validate the behaviours that the students displayed in the group, and to see if they were similar or different to the behaviours displayed by the same students in the classroom.

The Teacher aide and the Teacher were interviewed separately, and were recorded on an mp3 recording device, and as the phenomenological methods suggests, the following steps were taken. The findings from the interviews that were conducted in this research have been analysed using a phenomenological method, as described by McFerran and Grocke in Microanalysis in Music Therapy (2007). The process of this analysis involves a number of steps as follows:

1) The material was transcribed

2) Key statements were highlighted.

3) Statements that the interviewee made were then put into categories.

4) Themes were identified for each interviewee

5) Commonalities and distinguishing features in the themes from interviews, research journal, and discussion group are identified.

\section{Procedures for Data Collection}


Over the course of four weeks, nine students who attended the LSC, and one teacher aide (an aide in the classroom to which the students belonged) took part in group music therapy. There were three weeks of active music making, and one week with a videoed discussion group. The setting for the music therapy sessions was their classroom while their other classmates took part in other activities with their teachers. At any time, no fewer than 6 students took part in the music therapy sessions.

The clinical goals of the music therapy sessions were to facilitate group improvisational music therapy, and to encourage active musical participation of the students. Listening to a recorded excerpt provided material for reflection in the discussion group, and clinical notes provided me with material for a research journal. The research aim was to investigate staff and student perceptions and to find their opinions of the music sessions by conducting a videoed discussion group and staff interviews. ${ }^{2}$

Through the journal material I looked for written statements where I believed that the students were enjoying themselves (laughter), being engaged in the music (less verbal language, more music making), and working positively together (helping other students, getting along with each other)In the discussion group I looked at the verbal content of conversations, body language of students (open, closed-off), the input of the students (reflecting, letting others talk), and encouraging expression (verbalising their opinions, facial expressions). These written statements were looked at in order to determine how they felt

\footnotetext{
2 Initially, in this research project the 'discussion group' was designed to be a focus group. The focus group was videoed in order to analyse details (such as facial reactions, body language) from the members of the group. However, the video material collected from this group was not of a high enough quality to provide indepth analysis and coding. Therefore, in the interests of coherence, and with advice from examiners and supervisor, I have amended the research design in the final write-up of the thesis and have used the material that was collected in the discussion group to support the journal and the interviews in this research.
} 
about their music making, and to observe their socialising. The two interviews were carried out with the teacher of the students and the teacher aide to observe the behaviours displayed in the group, and to explore their perceptions about the role of music therapy in promoting sociability.

\section{$\underline{\text { Analysis }}$}

The discussion group and interviews were transcribed, analysed, and coded through observation and microanalysis. The material and conclusions from the data collected in the analysis has been presented in the findings section, and questions that have come from the data have been presented in the discussion section.

\section{Ethical Consideration}

This project was approved by the Southern A Massey University Human Ethics Committee (MUHEC), 2008.

The participants were provided with the highest level of ethical treatment I was able to deliver. The possible benefits of this project for the group were that the techniques used in music therapy could be assimilated into the classroom to increase variation and quality into the curriculum. I have tried to the best of my capabilities to make sure that all participants have been consulted respectfully and that their views about the music therapy sessions have been incorporated into future planning of music therapy in their school setting, and with the hope that they well be implemented by other music therapists in New Zealand in the future. 
As with any body of research there is a small risk that participants in this research could be identified as the New Zealand music therapy community of practitioners and students is still small. Every attempt has been made to de-identify participants, using pseudonyms and disguising the identity of the school. Also group communication is the focus of the study, so individual students' comments and behaviour have not been emphasised in the results. Personal harm that could occur whilst researching involved the possibility of challenging behaviours or aggression from some students in times of agitation or stress. It was an occasional risk at the LSC, but the staffs were trained to deal with these situations if they occurred. I made sure as a clinician that I attempted to reduce the level of stress in therapy and lead the discussion group in a relaxing, safe, and positive environment.

Risk was minimised as much as possible in the group, and the rights and opinions of the participants were respected throughout the research. In general the school and special unit were encouraging of all efforts to improve the curriculum and to promote the interests of students with special needs, and as a result, were interested in research being undertaken at the school.

\section{$\underline{\text { Research Design }}$}

This project has used a qualitative research design. The individualised approach towards the project complements the unique work that was carried out with the members of the group. The findings have come about through aiming to uncover the experiences of the participants of the music therapy group ${ }^{3}$, and reflect on my own experiences in music

\footnotetext{
${ }^{3}$ The framework for qualitative research originates from Aigen's chapter Writing the Qualitative Research Report (chapter 16), featured in Music Therapy Research $\left(2^{\text {nd }} E d\right)$, Barbara Wheeler, 2005, Barcelona Publishers, Gilsum.
} 
therapy. Qualitative research allows the reader to read an account of music therapy research that is specific to the individuals in this study.

The qualitative research process as described by Bruscia (2005) represents the participants of the study (humanistic enquiry), and "is created by the research inter-responsively, that is, as these elements influence and are influenced by all those involved in the research" (Bruscia, 2005, p.129). Qualitative research reflects the personal tone of this study, as it aims to represent the staff and student perceptions of music therapy.

This research draws upon several forms of data including a research journal to collect information, a videoed discussion group, and two audio recorded interviews.

The interview transcripts (verified by staff participants) and discussion group transcript are found in the appendices.

\section{$\underline{\text { Research Journal }}$}

After each of the group music therapy sessions and throughout the time I was conducting research, I wrote up my thoughts in a research journal. I wrote about my thoughts about the way the group worked, and highlighted any interesting findings and reactions in relation to the students and their relationships. The journal entries helped me to keep track of activities and to find recorded material for the discussion group.

The entries that arose from the journal were used for personal reflection. In this research, the journals helped to give reflect on the sessions leading up to the discussion group and to help choose which piece of recorded material that the students would listen to (along with the teacher aides' input, which will be discussed at a later point). 
The journal material is analysed in the data, as it adds another point of view to the research, and provides a voice for researcher. It also serves to cross the bridge between the role of the researcher and clinician.

\section{Discussion Group}

In the week after the last music therapy session, a discussion group took place. This group was made up of the students that took part in group music therapy. It took place in order to observe students' responses to their own music making, and to invite the students to engage in a discussion about music therapy, while listening to a selected audio recording from a music therapy session. The audio material was drawn from one of the three group music therapy sessions. The recording was discussed with the teacher aide, and together we selected a rhythmic activity for the discussion group to listen to. The discussion group was video recorded in order to watch how the students acted together in the group. Students were asked to express their opinions about taking part in music therapy.

The teacher aide was also invited to take part in the discussion group in order to encourage the students to participate actively in answering questions.

\section{$\underline{\text { Interviews }}$}

Two interviews were conducted with members of staff. The first interview was carried out directly after the discussion group with the teacher aide who was recruited from the senior class. The teacher aide was asked questions relating to the course of music therapy and the observations of the discussion group. As examples, asked to reflect on each student now, and comment additionally on their interactions and responses in the video session, and to ascertain their opinion of the compilation of musical activities that were used in the 
sessions. The second interview was conducted at a later date with the students' teacher. The teacher observed the videoed material from the discussion group and received the transcript, and this participant was interviewed following watching and reading the given material. The teacher was given the same questions as the teacher aide, excluding the ones that were specific to participation in the three music therapy sessions. For example I asked what they thought of that as an activity that the kids took part in, and if the music therapy sessions changed the social atmosphere in the classroom at any time. 


\section{Findings}

This section has been divided up into two parts. The first section will discuss the way that material in the music therapist's reflective journal was used from the group music therapy sessions to help select a recorded example for the discussion group to listen to. Next are the Interview findings, where first the findings from Brigette's interviews will be explained and described, followed by the findings from the interview with the teacher.

It has been important in the findings to address both of the research questions that this study focuses on. To remind the reader, they are:

One: To find out what staff and children think about the contribution of Music Therapy to socialisation in the classroom.

Two: To identify appropriate therapeutic activities that students and teachers (and I as therapist) consider helpful in promoting sociability in special education and to begin to recommend resources that could be used to stimulate and encourage group work and group goals in the classroom.

\section{Music Therapists Journal Findings}

The journal data was analysed to answer question two, where I have written personal accounts after the conclusion of each session. In coding the data, I have looked at how the students responded to particular group improvisational activities completed in the three sessions that took place prior to the discussion group. 
In the journal entries that were made after the three music therapy sessions had finished, I wrote about activities we had completed, the way that students reacted to the music, the way that they interacted with each other, and why I thought the students were acting the way they were. These occurrences have been divided up into the themes noted above, and brief excerpts have been included verbatim. Peer debriefing was used to help identify further trends in the music therapy sessions. I have also included a critique of my own work, where I explain how I worked in the group music therapy sessions with the students and the teacher aide.

To help in the coding of the data I paid particular notice to several key statements in the research question. These statements were

- Identifying therapeutic activities

- Make recommendations for Music Therapists

- Identify any activities that I think could be used to stimulate and encourage group goals in the classroom

- Addressing what students and teachers consider helpful in promoting sociability

All themes will be related back to the research question in their sections, and extracts from my research journals are included in the appendices.

\section{Identifying Therapeutic Activities}

Activities that took place in the three music therapy sessions were summarised from the research journal. In identifying therapeutic activities, I was looking for appropriate activities, or ones that the students seemed to respond to in a positive social manner. 
Music therapy enabled students to choose their own instruments and activities. This allowed the students to assert some control over the situation and use their own initiative in contributing to the group. This was particularly noticeable in a conducting game that the students took turns at.

Initially, the simple fact that the students were taking part was a main indication that the activities were holding their attention. On another level, when the students were told to listen in order to complete the activity and did so, and either waited for their peers to have their turn or to participate when reminded it was possible to note when they were fully engaged in the participating. The following is an example of a moment from an activity, where the students sat with their instruments and their eyes closed. They waited in silence until I tapped them on the shoulder to start playing.

"Each instrument is played per instruction and the students that have not been nominated to play sit in silence with their eyes closed. When the students all play together, a single cohesive rhythm is played...as the students are tapped on the shoulder, they desist playing." (5-9)

Another activity students take part in involves turn taking in a rhythmic activity where their names are divided into syllables:

"The students seem to be really into this activity and were all paying attention to each others' names and how many syllables were in each of their peers' names. They were also eager for it to be their own turns, but waited until the appropriate time." (12-15)

\section{Addressing what Students and Teachers Consider Helpful in Promoting Sociability}

In the research journal it is difficult to fully establish what the students and teachers considered helpful in the promotion of sociability. The journal is written from my perspective, reflects my own opinions, and my own personal thoughts. When the students 
were asked about activities in the music therapy group the feedback from the students was generally in the form of positive mono-syllable responses, such as "good" or when asked if they liked the activity they would say "yep." Interpreting students' responses is difficult because I am the one that makes the judgement about their opinions. I assume that as the students gave positive responses that they enjoyed the activities, and I see it as really important that the participants enjoyed the music group and the activities we completed.

"Out of the three active music sessions we had, there was only one negative outburst, or example of antisocial behaviour... The fact that there was only one outburst is another indication that the students were enjoying the activities we were doing." (16-19)

\section{$\underline{\text { Recommendations for Practice }}$}

I recommend that when starting out groups the first thing to make sure of, before continuing with research, is that trust is established in the group. I established trust throughout my placement through developing familiarity with the students, and making sure that I was an approachable person that the students could feel safe with. I have mentioned in previous journal entries that I felt I had a good relationship with most of the students at the LSC. I did whatever I could to help the students feel comfortable in taking part in the music sessions, and to give them the opportunity to feel safe within the group and within the musical activity. I am not saying that this would work with every group of students, but the response within this particular group of students was positive.

Another important factor is making sure that the activities that are introduced are appropriate for the group. With this particular group, they responded positively to activities 
that involved all their peers working towards a common musical goal, such as creating a soundscape or passing a rhythm.

The main recommendation I have made is positive reinforcement. I cannot emphasise using positive reinforcement enough. The reactions that came about from the students following the reinforcement were very promising as many examples indicate in the raw data of my research journal. I found that when I gave praise to the students, not only did they appear happier, and increase their interaction, but their peers reinforced the praise. I would like to share one example that happened shortly after a session.

At the end of the second group music therapy session a student became upset at losing a game. Each person was eliminated from the activity (a variation on a game of statues), and when he was eliminated and was asked to leave the class, he became upset and raised his voice and swore repetitively. At the conclusion of the session I went outside to see how he was. He was still quite agitated and was standing by himself hugging the school flag pole. I attempted to address his difficulty at losing the game, and he continued to swear. I decided then on another approach. "I finished off our conversation with telling him the things that I thought he did well in the session...He stopped interjecting when I began to praise him." (108-110) I noticed as soon as I moved away from addressing the bad behaviour and praising the good behaviour he had exhibited, his behaviour changed from being sullen with closed-off body language, to relaxing and desisting with the bad language he had been repeating.

\section{Identification of Activities for Group Goals in the Classroom}


Activities that could be taken from music therapy and applied to the classroom in this study appeared to be anything that involved all the group members, and that reflected the goals that the teachers had in place for their students. These were identified after consultation with the teacher and talking about possible gains that could happen in music therapy, such as increasing verbalisation and gross motor skills as well as socialisation. Giving the students the opportunity to learn something about their peers and the staff at the LSC was also met with a positive response. As I was using a client-centred music therapy approach, I found that I relied heavily both on the students telling me what they wanted to do, and their opinions about the music we had created. I was also aware that many of the students had developed a relationship with me, where they wanted to please me in our sessions. This may have meant they were open to my suggestions, but were not as 'honest' or able to provide criticism of our music therapy sessions. The common response when I asked what they thought of things we had done was 'good', or 'I liked it'. I felt that there was a great moment in the discussion group when Aaron made a suggestion about how the group could be switched with the PMP class that was happening at the same time as music, and how there could be a chance to play with other students. It seemed that although they got along well together, they felt that they could share this experience with more of their peers.

All of the students appeared to enjoy the experiences they had previously had with music, whether it be dancing, singing, playing instruments, or playing musical games. All of course had their own preference and interacted in different ways, but seemed to have a musical experience either way.

\section{Music Therapists' Personal Critique}


The research journal has served as a self-reflective piece of material, and as a primary data source. The important attribute to keep in mind is that the journal reflects the opinions and the observations of the researcher in a clinical role. When looking through the journal material I am constantly reminded that what I found was specific to the students that took part in the study. I was aware that the relationship that I had developed with the students had taken some time to establish, and if I had not established that relationship, then perhaps my findings would differ. I could assume that a student was not participating in an activity because of a specific reason, but I could be wrong. There could be many other reasons that I was not aware of.

\section{Interview Findings}

This section is divided up into themes that are related to the questions that were asked in the interviews. They are: (1) observation of students' reactions as they listened to the excerpt from their music therapy session (2) the interactions and responses of the discussion group (3) interviewees' opinions of musical activities in the sessions (4) changes in social atmosphere of the classroom perceived to be related to music therapy(5) feelings about being part of music therapy and interactions with students in the therapeutic setting, and (6) noted differences in sociability of students in comparison to other classes. I have provided specific examples from the interviews, similar to the format of the observations from the discussion group session.

Firstly, I present the teacher aide interview findings. I then present the teacher interview findings, followed by a summary of the interviews. 


\section{$\underline{\text { Teacher Aide Interview Findings }}$}

At the very beginning of the interview I explained to Brigette the way that the format of the interview. I wanted Brigette to feel comfortable with answering questions, and sharing her own opinions with me. I knew, coming into the interview that I would approach Brigette from a professional standpoint first, but also remember that we were friends and colleagues. I think to illicit an honest and meaningful response in this interview, it was important to create a relaxed atmosphere.

I did find that when listening back to the audio recording of the interview that I often was explaining the reasons why I did certain things in music to Brigette, and was often explaining the clinical music therapy perspective. I found myself realising when reading the transcription, that some of the things that Brigette was saying were regarding a music lesson, and not the therapeutic manner of the activities. I then took a mental step back and realised that as a researcher, I should not have been trying to explain the clinical standpoint. For this reason, I had a lot of material to go through in coding the interview data, but not all of the answers. The questions from a research perspective are there, but I have had a lot of material provided by myself (from within the interview) to go through. The interview with Brigette was semi-structured, and provided an opportunity for general discussion about the group music therapy sessions. It is also for this reason that I spend a longer time explaining the results from the Teacher.

The full teacher aide interview transcript is available in the appendices, using pseudonyms and line references. 


\section{Teacher aide observation of students' reactions in the discussion group}

I was able to collect a small amount of data from the first interview on this topic. Key words that were used were 'funny' (15), and 'familiar' (105). It was observed by the interviewee that Gavin was very good at rhythms and can start at any point. He has rhythm in his body. I found it hard to get Brigette to talk generally about the observations of the discussion group. We both were side tracked about small occurrences that had happened in the session that did not have a lot of relevance to the research.

\section{Teacher aide's observations of interactions and responses in the discussion group}

Brigette had a feeling that where the student responded to discussion group questions, that not all of them were answering honestly. She did feel that Jackie did come through with moments of self-expression. I have interpreted a statement that Brigette made as a realisation on her behalf. She realised in this interview that she had not been observing, or did not think about the way that some of students do not like particular sounds. She said that this is something she will have to work on in the future. Through being part of the discussion group, Brigette herself has become more aware of the students' sensitivity to music, as "something to think about from this point in time" (77). Brigette also noticed that Karrie has shown an improvement in her rhythmic skills from what she had displayed previously. 


\section{$\underline{\text { Teacher Aide opinions of musical activities in the sessions }}$}

In the interview I lead the conversation about this. It was established that Brigette enjoyed the rhythmic activities, and she saw them as being helpful with gross motor skills for some students, such as Karrie, whose use of rhythm improved in the music therapy sessions.

"Ah, I think the rhythmic ones I really liked...I could see for example Karrie improve herself. She really did, because in the beginning she didn't know any rhythm at all." (88-89)

The above words from Brigette are meaningful, as she has observed a change in playing with a student from within the course of music therapy.

\section{Changes in social atmosphere of the classroom through music therapy}

Brigette discussed with me how students change when they have music, and stated that they pay more attention to the group and class (assumed to be in comparison to the attention that they pay in the ordinary classroom).

Feelings about being part of music therapy and interactions with students in the therapeutic $\underline{\text { setting }}$

This question brought about what I understood to be a really meaningful moment in the interview. When I asked Brigette what her feelings were about the group, she responded with "I think that I have something special with the kids because of the music lessons together" (143-144). She went into further detail, explaining that it was nice to see them in another setting outside of the classroom. She identified with being part of the group. I understand that this feeling allowed Brigette to be part of the group, and interact as part of 
the music therapy group. It appears that she appreciated this exclusivity and that it has been a positive outcome for her.

\section{$\underline{\text { Noted sociability of students }}$}

Brigette said that the students were already "very socialised" (160). However, along with this statement, it is also said that they were impressed with the way that they helped each other (generally), and they were observant, very kind, that they helped each other, and that although they can become selfish, in the end they are very nice students.

\section{Final thoughts on interview}

I have concluded the findings of the interview with the teacher aide with a few points. I

have reflected on the obvious shortcomings of the interview with Brigette as being mainly of my own inexperience with the interview process. If I had a chance to do the interview again I would not have conducted it straight after the discussion group, so that we both had time to reflect upon what happened. I would also step away from the clinical perspective and put more of an emphasis on the research. I would also explain the questions further so that I knew that Brigette understood what I was wishing to find out.

I can establish, in relation to the research questions, that Brigette enjoyed taking part in the discussion group and the music therapy programme. She felt as if she was a member of the group, which is important for the inclusive goals that I had in the running of the sessions. I can also see from the data provided that she has taken something from music therapy to 
use for the future, such as working in a group, paying attention to the needs of students, working to the level of, and listening to the students.

\section{Teacher Interview Findings}

Following the conclusion of the discussion group, the consenting teacher was asked to watch the video and read the transcript of the discussion group. She was then interviewed, and asked to discuss her observations within the discussion group, reactions to the growth of the group, and opinions on their development over the course of music therapy.

As well as using the data that the teacher aide supplied at the conclusion of the discussion group, I also asked the teacher to supply some feedback about the video recording. The purpose for this was to validate the behaviour that the students displayed in the group, and to see if these behaviours were similar or different to the behaviours displayed by the same students in the classroom.

A copy of the full transcript with name changes and line references is available in the appendix.

\section{Teacher Observation of Students' Reactions in reviewing the Discussion group session}

The key words that came up from the interview was the observation that the students appeared to be focused, listening, repeating rhythms, and being fairly engaged. Engagement is a common theme in the interview material. In the discussion group, the students are noted to be somewhat more engaged than they would be in the classroom. The explanations for this higher level on engagement are discussed later in this section. The 
teacher and the teacher aide both talk about the moment when the students listen to and copy the rhythmic example played on my computer as a standout point (14-16).

\section{Interactions and Responses of the Discussion group}

The Teacher uses the following words to describe the interactions and responses of the group: standard, very engaged, and enthusiastic $(19,20)$. The teacher mentioned that the students in the discussion group may possibly be a little bit more enthusiastic about being in the group than when they are in class. Possible reasons for this as interpreted by the teacher, and in brackets by myself were: the slightly informal environment (not made to sit at a table facing the front as a possibility), that a lot of them like music (is a common interest), they enjoy discussing music (a common topic with their peers), and the size of the group being smaller, consisting of people that they are comfortable with (good relationships in the group, with manageable numbers where students can be addressed individually).

\section{Teacher Opinions of Musical Activities in the Discussion group}

The teacher specifically talks about the drumming activity as being good as it contains coordination skills, has the students working in a challenging musical activity (with having two groups going at the same time), and that it is a good source of interaction. With these comments, I can presume that it was a successful activity for the students that took part in it. 


\section{Changes in Social Atmosphere of the Classroom through Music Therapy}

Some of the key words that were used to talk about the changes in social atmosphere were: change, attention, lighting up, enthusiastic, and engaged. In observing the discussion group tape, it was clear that there was a positive change in the social atmosphere of the students that took part in both the group music therapy. The teacher mentioned in their interview that the students were engaged in activities in the discussion group "than maybe they would be in class" (41). The reasons for this possible increase in engagement (as stated by the teacher) are that they may not enjoy what they do in class, and that the atmosphere of music therapy may be more engaging and light-hearted. It is concluded that the students have possibly reacted to this social atmosphere more strongly than the social atmosphere of the classroom, because they may enjoy the activities that they do in music more than the activities that they do in class.

\section{$\underline{\text { Noted Differences in Sociability of Students in Comparison to Other Classes }}$}

The teachers' answers indicated a positive outcome from the discussion group observation. The Teacher used the terminology "more engaged" (47) for describing Billy's sociability. In the classroom Billy had a tendency to withdraw, but in the teachers' observations of the video material, Billy was "pretty much engaged" (49), and he "stopped himself" (50). I interpreted this as being a kind of self-regulation, where Billy was aware of his behaviour and was able to hold himself back from being disruptive. The Teacher also noted that when he did stop himself, he was able to re-engage himself back into the group. The reasons for this could be due to the different setting of the discussion group or the fact that the size of the group is smaller. The Teacher was not absolutely sure why he was able to re-engage, but 
this behaviour was never observed in the classroom. It was also observed that Simone was focused in accordance with her abilities to do so. She responded appropriately, asked appropriate questions, and was not tangential like she can be in class. Andrew was displaying his standard responses in the group, and the Teacher explains that he will only respond if you engage with him individually. He however is "into his music" (63), and it is understood that was listening, but was not able to actively respond to the group. Aaron was noted as being a "bit more forthright" (69) than he would be in class, and that Gavin, Karrie, and Jackie displayed mostly typical behaviours, except that Karrie was quieter than in class was a "little bit more focused" (73) in the discussion group.

\section{Discussion of Interview Results}

Ansdell, Pavlicevic, and Procter (2001) write that a strategy in validating work is getting "expert opinion" (Ansdell et al, 2001, p.19), and this is relevant to my study, as the teacher and teacher aides are the experts. Through the interviewing process, they have given me their expert opinion in education on the course of music therapy and the impact on the group. It was very helpful in my research to have conducted the interview with Brigette and the Teacher, and the interviews were a good way to provide closure to the discussion group, as well as to the four weeks of data collection in the music therapy sessions.

It was important for me to help Brigette feel that she was an important part of the music group, and a co-facilitator of the project. This was the reason that I chose a semi-structured interview; we were both contributing to the conversation, and it did not just consist of me asking questions and Brigette giving answers. The only issue that I have with this interview is the muddling of perspectives from me as both music therapist and researcher. I am aware 
that I should have had more of a separation of these two roles, and I found that when looking at the interview material, that many times I was explaining the actions of the music therapist, and not just collecting data as the researcher. I think if I were to do the interview over again, I would have the first part be more structured, with more formal questions. For the next part I would have an open conversation about the music and the group.

Some of the questions were not fully answered by Brigette, and I felt that there were two factors at work here. Firstly, maybe my questions were not worded correctly, and should have been explained in more detail. Secondly is, English is Brigette's second language, and there is a possibility she did not fully comprehend my questions, or I misinterpreted her answers. I did consider e-mailing another interview to her, but felt that I did have enough material to expand upon in the data that I had already collected. 


\section{Discussion}

As a group, the students already had a personal relationship with one another. From the relocation of the LSC to the new site, these students, originally from two classrooms, had been put together in one classroom. As they spent more time together in their new class, their relationships appeared to change, and they became more familiar with each other. The amalgamation of the class seemed to provide an opportunity for a new social group to form.

A similar occurrence happened in the formation of the music therapy group. The students had all participated in either group or individual music therapy before this group was made up. Because attendance required consent from parents, this group was smaller than the other sessions, which ran for all of their classmates once a week. The implications of this for other students could be that they feel excluded or left out because they were not given consent to attend. There was no preference of my own on which individuals would take part in the research project, but only the students that had obtained written consent from their parents would be able to attend.

In this project I endeavoured to find the answers to my two research questions - finding out what staff and children thought about the contribution of music therapy to socialisation in the classroom, and secondly identifying appropriate therapeutic activities that students and teachers (and I as therapist) consider helpful in promoting sociability in special education. In conclusion I found that overall; the students enjoyed being part of a music therapy group, and those activities that required social interactions were helpful in promoting positive sociability within the group. 
To address these goals, I reviewed journal material from the group music therapy sessions, the video from the discussion group, and two interviews with the teacher aide working with me in music, and the students' teacher. I found that group music therapy in this particular setting encouraged positive social interaction between peers. Group music therapy offered an alternative setting to the classroom for students to spend time together. The students appeared to have enjoyed taking part in music and feedback from interviews, journal, and discussion group strengthened this observation. The most appropriate therapeutic activities occurred when students were working together to complete a task and where they were encouraged to help each other to take part in music.

This discussion section has been divided up into two topics. The first section reflects on what changes I could have made to the processes undertaken in this study, and what I would have done differently if I had another chance. The second section discusses the findings section of this study, and makes general observations about the data collected through the music therapy sessions, discussion group, and interviews.

\section{Possible Changes}

On completing the requirements for data collection, I could not help but think if I could do it all over again, what I would do differently?

I think that it definitely would have been worthwhile doing more practice in interview skills and techniques. I think that would have helped me approach the issues with the first interview I conducted, and help to draw more relevant data from the transcript. 
The initial plan of including a focus group in my research was changed as the material that was collected was not adequate enough to provide a deep level of analysis. For this reason, the group was changed to a discussion group, and used to provide a transcript for the teacher interview.

I would have changed the location of the discussion group so that we all had room to sit and so that all the students would fit in the camera frame. It was disappointing that I was not able to capture all the students on film simultaneously, but I did feel that I made a good decision with placement of the camera, and focused on the appropriate selection of students. I think that the environment the students were in (with the camera obviously focused in on them) may have inhibited their responses somewhat. An audio recording of the discussion group may have been less invasive, but not necessarily as sufficient as a video recording.

There was limited time available with the group, and this meant that I was only able to conduct three music therapy sessions, at a rate of one per week. I could have asked for the frequency of the sessions to be doubled in order to get 6 sessions completed, but I thought this would be too disruptive to their class timetable. The class had already made such an effort to make sure that we had a space to work in where we would not be interrupted and in which the students felt comfortable. There were also other teacher aides given to our group for extra support in case we needed it. I did not want to feel like I was taking advantage of the generosity of the class by asking for more favours. Also, and much more important, is the possibility that the students may not have wanted to have more music therapy sessions. They may have wanted to have more than just the three, but they were aware that Brigette was going back to her homeland and that would ultimately signal the 
end of the group. Having a different teacher aide may have changed the dynamic of the group, and the discussion group session was set in the last week of term, which provided a convenient point of closure.

The observations that I made first were of the individual responses of the students in the discussion group session through reviewing the video recorded material. As in the discussion group, there was no possibility of being able to fit all members of the group in the frame for video recording purposes. This was really unfortunate, but something that I could not control. When I was not behind the camera I had the camera on the tripod fixed on Andrew, Simone, Billy and Aaron. Andrew is withdrawn for the entirety of the session, and only looks up and verbalises when he is addressed directly. Simone sits with her hands crossed, eyes looking around the room. She reacts to sound like other students laughing or names being called out. Billy sits and jiggles around occasionally. As he has a diagnosis of ADHD, his behaviour is understandable, and expected. When people are talking however, he does pay attention, and this is information I noted from reviewing the video recording. It was important for me to position the camera in this way as it enabled me to view the students that I may not have conversed with as much in the group as with others.

As the topic of my thesis concerned promoting sociability and perceptions of music therapy, I found it hard not to look for evidence and argue that music therapy was beneficial to the student population I was working with. It is not that it was hard to find evidence it was just that the aim was not to find evidence. The aim was to use and document the course of music therapy sessions, and to report on the perceptions of the students and staff of the school. 
I found that it was also very hard to separate the role of the music therapist and researcher. In the first interview that I held with the teacher aide involved in the project, it is obvious when looking at the transcript how blurred the lines were. In the second interview not only is there more information, but it is more to the point, and I definitely was wearing my 'researcher's hat' that day.

\section{Findings and General Observations}

Through working as a music therapist for the majority of the year, I found that I ended up rationalizing what I do to the others around me, and to myself. It has been a very selfreflective path, where I have been constantly trying to understand the steps I am taking to promote goals, and how my goal setting has affected work with my clients. If there was a battle to be had, it would be trying to show people that what I am doing is beneficial and relevant to the client base, and that it is worth having me, or another music therapist around. What was even more of a battle was affirming my belief that I was making the right choices and working for the benefit of the students I was interacting with, while at the same time not letting this motivation shape or skew the perception I had of my research.

Due to the limited number of sessions that were conducted, this small amount of material gave me the opportunity to reflect on the findings of each music therapy session, and draw conclusions from the overall exercise.

I found that the more time that passed with the project, I was able to see responses from the students, and was able to come to terms with our relationship in music. I became aware that all of the students relied on me to provide this service. This was a forum that differed 
from their classroom goals, in that they were able to be in, as the teacher said, a lessstructured environment, and contribute when they wanted to, not when they were told to. I have referred earlier to the Baron et al (1999) concept of identity where Erikson is cited as writing that identity is chosen in adolescence. Individual identity does contribute to the function of a group If an individual identifies with another group member, then it could be a successful matching of identities. In this research I have aspired to encourage the development of positive social interaction between individuals.

Wheeler and Kenny (2005) write that the history of qualitative studies in music therapy, were initially less formal in design, and in the form of clinical journals and in studies that gathered little publicity (p.59). The shift towards a more formalised and authenticated research in this subject has bought about much debate in music therapy research (p.60). The goals of qualitative research studies in music therapy are therefore understood to have a holistic basis, represent the participants and the researcher, and create formal research material. 


\section{Summary}

The promotion of sociability in education is an important factor in the classroom. The development of peer relationships can be crucial to the individual growth of the student especially during adolescence.

This group began as an opportunity for classmates to spend time together in another social setting. The music therapy sessions were planned so that they would reflect the social and supportive needs of the students and provide an atmosphere where students could participate freely in music. I encouraged the students to offer their opinions on the music we were creating and gave them the opportunity to decide what we would do as a group, and I supported their choices. This is particularly important for adolescents with special needs as they can often be isolated from other people in their age group due to challenges with communication. The main aims of music therapy in this setting are to increase meaningful conversation, develop creative thought processes, encourage participation in a social atmosphere, and create an environment where students can feel free to explore their own musicality.

Music therapy in special education can be understood as complementary to the education of the student and can offer different avenues of learning, and alternative ways of thinking. In this project, I was offering group music therapy sessions with students as another means of increasing social interaction between those particular peer groups. 
The question is did the music therapy programme help to encourage socialisation with this particular group of students? Some trends that I did start to notice were the development of positive social behaviours and increased positive interaction within the peer group. From within the sessions leading up to the discussion group this was shown through students waiting for their turn to play, listening to instruction, and listening in silence when others were speaking. Often a student that needed encouragement would get it from a more able student, and participants were generally respectful of each others' playing, choosing only to feed back on the group at the discussion group where they had been asked directly.

The sociable skills that were displayed in the discussion group were a really positive outcome for both the students, and this research. Whether or not it was solely the music therapy sessions that actually made a difference to the socialisation of the group is unknown, as clearly many other factors come to bare on the lives of these students. The various other learning opportunities and activities they participate in all affect their lives daily. However, music therapy definitely offered an alternative to achieving the goals set about by the LSC. An atmosphere where music was the main form of communication gave students and their peers the chance to work together in a safe and supportive environment, and in an alternative setting from their regular classroom. This environment encouraged positive peer interaction and socialisation. 


\section{References}

Amir, D. (1992). Awakening and Expanding the Self: Meaningful Moments in the Music Therapy Process as Experienced and Described by Music Therapists and Music Therapy Clients, UMI.

Ansdell, G., Pavlicevic, M., and Procter, S. (2001). Presenting the Evidence: a Guide for Music Therapists Responding to the Demands of Clinical Effectiveness and Evidence-Based Practice. London. Jessica Kingsley Publications.

Baron, S., Riddell, S. and Wilson, A. (1999). The Secret of Eternal Youth: Identity, Risk and Learning Difficulties. British Journal of Sociology of Education 20(4), 483-499.

Borczon, R. M. (1997). Music therapy: group vignettes. Gilsum, Barcelona Publishers.

Bunnell, T. (2007). Music Makes a Difference: A practical guide to developing music sessions with people with learning disabilities. London, M\&K Publishing.

Clair, A. A. H, and George, N. (1989) Willem van de Wall: Organizer and Innovator in Music Education and Music Therapy. Journal of Research in Music Education 37 (3), 165-178

Erikson, E. H. (1995, 1951). Childhood and Society. London, Random House.

Erkkila, J. (2004) From Signs to Symbols, from Symbols to Words-about the Relationship between Music and Language. Music Therapy and Psychotherapy,

Goodman, K. D. (2007). Music Therapy Groupwork with Special Needs Children; the Evolving Process. Illinois, Charles C Thomas Publisher LTD. 
Kim, J., Wigram, T. and Gold, C. (2008). The Effects of Improvisational Music Therapy on Joint Attention Behaviours in Autistic Children: A Randomized Controlled Study. Journal of Autism and Developmental Disorders 38, 1758-1766

Lewis, A., and Porter, J (2004). Interviewing children and young people with learning disabilities. British Journal of Learning Disabilities 32 (4), 191-197

Malekoff, A. (1997). What's so Special about Group Work? An Introduction to Tradition and Theory. Group Work with Adolescents. New York, the Guilford Press.

McFerran, K., and Wigram, T.(2002). A Review of Current Practice in Group Music Therapy Improvisations. British Journal of Music Therapy 16(1), 46-55.

McFerran, K. (2008). Music therapy Groupwork with Special Needs Children: The Evolving Process. Australian Journal of Music Therapy 19, 95-97.

Nordoff, P. and Robbins, C. (1977). Creative Music Therapy: Individual treatment for the handicapped child. New York, John Day Books in Special Education.

Olson, J. L. ,Platt, J.C. and Dieker, L.A (2008). Social Skills and Peer-Mediated Instruction. Teaching Children and Adolescents with Special Needs. Ohio, Pearson Merril Prenctice Hall.

Pavlicevic, M. (1997). Music Therapy in Context: Music, Meaning and Relationship. London, Jessica Kingsley publishers.

Potter, M. J. (2007). How does a music therapy student facilitate verbal interactions in a group of developmentally delayed adolescents? Unpublished Master of Music Therapy Thesis, New Zealand School of Music. Wellington, Victoria University, Massey University. : 65.

Rickson, D.J, and McFerran, K. (2007). Music Therapy in Special Education: Where are we now? Kairaranga 8(1). 40-47. 
Rickson, D.J, and Watkins, W.G. (2003). Music Therapy to Promote Prosocial Behaviours in Aggressive Adolescent Boys-a Pilot Study. Journal of Music Therapy 40(4), 283-301.

Standley, J. M. (1996). A Meta-Analysis on the Effects of Music as Reinforcement for Education/Therapy Objectives. Journal of Research in Music Education 44(2), 105-133.

Strange, J. (1987). The Role of the Music Therapist in Special Education. Journal of British Music Therapy 1(2), 28-31.

Twyford, K. W. and Watson, T. (2008). Integrated Team Working. Music Therapy as part of Transdisciplinary and Collaborative Approaches. London: Jessica Kingsley Publishers.

Tyler, H. M. (2002). Working, Playing and Relating. Issues in Group Music Therapy for Children with Special Needs. Music Therapy and Group Work: Sound Company. A. R. Davies. London, Jessica Kinsgley Publishers.

Wheeler, B. L. Shultis, C.L, and Polen, D.W. (2005). Clinical Training Guide for the Student Music Therapist. Gilsum, Barcelona Publishers.

Wigram, T. Pederson, I., and Bonde (2004). A Comprehensive Guide to Music Therapy: Theory, Clinical Practice, Research and Training. London, Jessica Kingsley publications.

Wigram, T. (2004). Improvisation: Methods and Techniques for Music Therapy Clinicians, Educators and Students. London, Jessica Kingsley Publications. 


\section{Appendix 1}

\section{Excerpts from Research journal.}

$27 / 08 / 2008$

1 As we have not had a suggestion on the activity, we play a familiar activity that we

$2 \quad$ Have played in class where the students have to close their eyes and play when they

3 are tapped on the shoulder. The music making in the session only really starts after

410 minutes of organisation and explanations. There is absolute silence when I ask

5 for it. Each instrument is played per instruction and the students that have not been

6 nominated to play sit in silence with their eyes closed. When the students all play

7 together, a single cohesive rhythm is played, which has been dictated by the bongos.

8 The rhythmic instruments join in, and the melodic instruments play appropriately

9 over the top. As the students are tapped on the shoulder, they desist playing.

10 After some more discussion about this I began a conversation about our names and

11 about the syllables in each of our names. We went around the group clapping

12 rhythms to each other's names. The students seemed to be really into this

13 activity and all were paying attention to each others' names and how many syllables

14 were in each of their peers' names. They were also eager for it to be their own turns,

15 but waited until it was the appropriate time.

$25 / 09 / 2008$

16 Out of the three active music sessions we had, there was only one negative 
17 outburst or example of antisocial behaviour. This was caused when William would

18 not cooperate with game rules. The fact that there was only one outburst is another

19 indication that the students were enjoying the activities we were doing.

20 William and Simone made some lovely suggestions in the soundscape routine,

21 William choosing 'bubbling mud', with a cylinder shaker, and Simone choosing

22 'aeroplane' with a tambourine (holding it above her head while saying what it

23 was). After talking to William at the end of the group he had said that he had only

24 ever driven through Rotorua, meaning that he had not physically seen or heard the

25 bubbling mud, but was able to make associations with the place through learned

26 information. There was an incident at the end of the session with William becoming

27 angry that he lost the freeze game. He became upset that he had to leave, and

28 began to raise his voice and swear. At the end of the session I went and found him

29 outside. I talked to him about why he got so angry, and explained why people do not

30 like swearing. I finished off our conversation with things that I thought he did well in

31 the session. I said that he did some wonderful work on rhythms, and that the

32 'bubbling mud' was such a great idea. He stopped interjecting when I began to praise

33 him. 


\section{Appendix 2}

\section{Full Transcript Discussion Group}

1 E: Just Pretend that's it's not even there. (Students move around and re shuffling seating).

2 Do you want to sit on the ground?

3 Jackie and Karrie: Yeah

$4 \quad$ E: You can sit here if you like...

5 E: All right, so... you're all comfy?

$6 \quad$ Karrie: Yeah

$7 \quad$ E: That's good.

8 E: So, okay. So, this is the very, very, very, very last group

9 Gavin: is it because Brigette is going

10 E: yeah, yeah we talked about that last week, didn't we...about...Where is Brigette off to?

11 G: To her country

12 E: What's her country?

13 Karrie: (says name of country)

14 E: Yeah, very good

15 G: coz it starts with a (first letter of country), that's the same as my name! (A playful

16 atmosphere, relaxed)

17 E: That's right, it does.

18 Simone: oh wow, camera...

19 E: So, We've got in the group today...who is here?

20 Karrie: me!! The birthday girl (smiles and waves) hi. And beside her is (K: Jackie) Jackie

21 Potatey.

22 Gavin: And then DC...Gavin (Simone: Simone) Billy, with the medal, (Simone: Simone, and

23 Andrew), hi Andrew, hello. (one and only time he looks up during the discussion group) 
24 we have got Brigette and (other teacher aide) (laughter) and Emma. Hi, here's my fingers

25 (waves finger in front of camera)

26 Okay, right...So we are not going to be able to see exactly everyone in the frame but that's

27 okay, I think we'll put the camera right....here (focusing in camera on Aaron, Billy,

28 Simone, and Andrew) Sweet.

29 So, what we are going to do today is listen to a little exercise that we did a few weeks ago.

30 So, we had... how many groups did we have

31 Jackie : ummmmm

32 Gavin: two...three.

33 Emma: Yeah three. And we did, we did lots of stuff in them. Can anybody remember what

34 activities we did in it?

35 Gavin: Communication?

36 Billy (with arm up): Communication

37 E: We did communicate with each other. How did we communicate? (Pause)

38 E: How did we communicate? What did we use? (Jackie leaves room to go to bathroom)

39 Billy: We communicated with our instruments

40 E: yeah, we did some instruments, that's really good. So we used music to help us

41 communicate. okay, I might just wait for Jackie to come back to listen to this too, or should I

42 play it, (Gavin: yeah) what do you think...play it? (Karrie: yeah)

43 Aaron( gets up): just need to get a drink of water

$44 \quad$ E: okay. (laughter).we'll wait for those guys. Does anybody else need anything?

45 Gavin: no!

46 Brigette: if you need to go to the toilet the time is now (some mumbling from me)

47 E: Okay, so, who wants to tell me some of the stuff that we did? What we do with our

48 music?

49 Gavin: we played instruments 
50 E: We did play instruments. We communicated through our instruments. That is very good.

51 What else was a big part of our music? (pause) We had our instruments, but what else did

52 we have? Something that we had was each other in the group, so that's what being part of

53 the group means

$54 \quad$ Karrie: Worked together

55 Emma: yeah, we worked together. What else could we do in the group...with other people

56 Karrie: sing E: yeah

57 Gavin: Do choir (but does gesture of conductor)

$58 \quad$ E: yeah, what was that one called where we...

59 Jackie: (verbalises sounds like 'e-ka')

60 Gavin: hand moves

61 E: yeah, you just about had it....what is it?

62 G: Percussion!

63 Karrie: Drums

64 E: Con...

$65 \mathrm{G}, \mathrm{J}$, and $\mathrm{K}$ : conducting!

66 E: Yeah that's right. So we did conducting, and we also did, like Sound effects and things.

67 Karrie: we did this and this (hand gestures)

68 E: oh yeah! The, the elastics, right. Yeah, good remembering. Ok so were gonna listen to a

69 little example of a song that we did. So what I want you to do is I just want you to have a

70 listen to it for a wee while, and then we might have a little chat about it. Is that cool Billy?

71 Billy: Yeah (he is at this point being slightly disruptive)

72 E: Sweet, all right...Okay I'll just put it

73 Billy: I can't see

74 E: you can't see, can you hear?

75 Simone: not scary 
Billy: Emma I can't see

77 You can't see the? Oh you don't need to see the computer coz we're just listening to it. It's

78 all good. I'm just doing this so that I can find the timing (I spend a few moments cuing up the

79 correct audio file)

80 E: okay listening to this one here... (getting timing on laptop correct)...

81 Listening to example. I get behind the camera to get all students in the frame. Students are not really talking, and are clapping and listening to the example. All listening quite intently

to the music. Listen to approximately $\mathbf{2}$ minutes of material whilst clapping.

84 Simone: hello Emma (as I walk across the room)

85 Okay, have we had enough of that?

86 Karrie: yeah (E: okay). (I stop the recording)

87 E: So...does anybody remember taking part in that music? (Pause) Do you remember being

88 able to do it? Being on that recording, so you were part of that recording?

$89 \quad$ Karrie: I do

90 E: you do? So what were you playing?

91 Billy: the instruments

92 E: Yeah, yeah. The instruments being like...

93 Billy, Karrie: the hands

94 Jackie: knees

95 E: Because There was one group going (clap rhythm), and there was another group going

96 (claps rhythm). Do you remember what part you were doing? (Pause) Does anyone

97 remember if you doing that one (first rhythm)? Hands up if you were doing that one

98 (Billy and Gavin hands up).

99 You were doing that one? Okay.

100 And What about Brigette's group, that was going (second rhythm). Hands up if you were in

101 Brigette's group. 
102 (Aaron puts his hand up) excuse me... I can't remember what group I was in

103 Jackie: Emma!!

104 E: What about now? What one do you think you would be able to do now? Do you think you

105 would be able to do one of them or both of them now?

106 Aaron: was I in your group?

107 E: I'm not sure (Jackie: yes, yep)...I can't remember...you remember (addressing Jackie), was

108 he in, in the group that I was doing (nods yes), oh...okay, okay.

109 E: so, what did we think about what, what we were listening to?

110 Gavin: it was good

111 E: could you tell who was doing what? Could you tell who was in the group?

112 Gavin: No

113 How come you couldn't you tell who was in the group?

114 Gavin: Coz there was no pictures. (Says in a comical inaudible voice)

115 Jackie: what?!

$116 \quad$ E: there was no what?

117 Gavin: pictures!

118 (Laughter from Simone, then Gavin)

119 Brigette: there was no pictures...

120 E: Pictures, right, yeah okay...and no... (Cut off by laughter) That's very profound Gavin,

121 that's very good. And so guess because nobody was talking, right? What did you think

122 about being part of the group? Not necessarily like in that piece of music that we

123 played, but what about taking part in the music (pause) Was it okay?

124 Or did you not like taking part in it? What did you think? Like really, really honestly. Did you

125 Like it, or... (Cut off)

126 Karrie: I liked it

127 Billy: I liked it, it was good

128 E: You did like it? 
130 E: What do you think we could have done to make it even better?

131 Gavin: played some electric guitar.

132 Aaron: (puts hand up) E: Yes? Aaron: do different things

133 E: do different things? Like what kind of different things?

134 Aaron: like any we can think of?

135 E: yeah...like different kind of games?

136 Aaron: or different kind of rhythms and that

137 E: Would it have been as good if there were like less people

138 Karrie: yeah

139 E: Yeah? Okay. What about different people. Do you think it would have made a difference?

140 Aaron: some people from PMP can come over to music and some of us can go to PMP

141 Simone: after lunch

142 E: So, that was going on at the same time as you had music? Was it PMP (Karrie: no)...Or are

143 you saying that at another time we could take it at another time

144 Aaron: no, because we could swap with others.

145 E: oh okay, so you could have new people and...

146 A: but some from PMP to music, and some from music to PMP

147 E: Okay, right...right so. How about we go around the group now, and we think of

148 something

149 to say about a person who took part in the group? Would that be okay? So, we could

150 say... What can we say....Brigette? Would you like to talk about anybody in the

151 group?

152 Brigette: Yes I think that most of you took very good part in the music, but I noticed that

153 whenever you were in the middle, some of you were lying down on the floor and you

154 were not concentrating. So I think it is best if you are sitting up and paying

155 attention to Emma. Yeah, that's it.

156 E: Thanks for sharing that Brigette. I would like to say from this group...I really liked the 
157 Way that you were all encouraging of one another.. any kind of instruments you were using

158 or any kind of activity you were doing....whenever somebody needed help, you guys all

159 helped each other, and I thought that was really, really nice.

160 (Other teacher aide talks a bit, about success in rhythm and listening skills)

161 Brigette: and Karrie, you

162 Karrie: who ME??

163 B: yes you, you really got it

164 Gavin: ( claps) Wooo-hoo Yeah Karrie, it's your birthday, we're gonna party like it's your

165 birthday. (Simone laughing claps. Laughter)

166 E: Now, would anyone else like to comment on the group, or about anybody in the

167 group. Yeah, would anyone like to say anything? (More laughter from Simone. Gavin

168 laughs, so does Billy. Jackie says Billy...Gavin, telling them off). I'm sure you guys could think

169 of something to say...what about, um...let's see. So, it would have been different if there

170 were different people were taking part.

171 Aaron: yup, yup.

172 E: Who out of the group did you; did you enjoy playing with other people more than others?

173 Yeah Aaron?

174 Aaron: yeah, I enjoyed playing with other people

175 E: Yeah?

176 Gavin: I liked playing the drums

177 Yep. Okay what did you like about playing the drums?

178 Gavin: because I wanna be a drummer when I grow up. (E: Oh cool) Actually I'm already

179 grown up (laughter)

180 E: did you enjoy playing the drums when it was just you on drums, or when everybody was

181 playing? G: when it was just me. E: When it was just you...

182 G:yep

183 Jackie: yeah, yeah (Sarcastically) 
Did anybody like it when just Gavin was playing drums by himself

185 (Billy puts hand up, I think he says yeah)

186 Karrie and Jackie: no!

187 Gavin: Oh come on! Am I that bad? Laughter

188 Jackie: yes.

189 E: Okay how come it wasn't, like, yeah...Karrie, how come?

190 Karrie: like...like this (waves hand up in air as if playing drums wildly...this is imitated in the

191 screen shot by Billy)

192 E: Okay, so, how could describe that? Sorry to pick on you Gavin for a second. Karrie: sorry

193 for everyone picking on you Gavin! (laughter)

194 Gavin: no! go...no, go (encouraging Karrie to talk) E: I think, I think...yeah sorry Karrie?

195 K: when he's doing this (air drumming), it was noisy. (Simone laughs)

196 Gavin: drums are noisy you know

197 Karrie: it hurts my ears...

198 G: I can't turn it down, you know...

199 E: Well, You could kind of turn it down though. How could you, from what you've learned,

200 turn it down a little bit. Billy: slowly, E: Slowly? Yeah Annnnd

201 G: softly. Hi!!!! (Waves to camera)

202 E: so... slowly and softly ... Hi, and that's Karrie down there. Karrie can you show what you

203 were doing before when you were showing how to play?

204 Karrie: okay! (Gets bongo drums, plays loudly). You were like that,

205 Gavin: that's not loud!

206 Karrie: like that! (some chatter) E: Okay, right Um, I think it's really important in a group

207 when you're playing, to listen to each other. And if you are 'too loud', whatever too loud is,

208 then what do you have to do?

209 Gavin: play softer! E: Yeah, okay! Or do what other people in the group might be doing? 
210 Billy: (hand up) Emma, Emma I was listening to the drums (does air drumming) E: Banging

211 the drums? B: yeah...E: And what did you think about the banging of the drums?

212 B: it was too loud and noisy, and he couldn't help it. E: Ah, right, okay.

213 Teacher aide talks. E: It can be a little bit hard to listen to, eh? Yeah, cool. Alright, were

214 there any last (Simone puts hand up) requests?

215 Simone: Simone! (yes, Simone?) ah...guitar E: The guitar? Simone: yes

216 Karrie: yeah, William's not here today

217 E: Oh yeah!

218 Simone: okay, can we?

219 E: Yes, certainly. (guitar gets passed to Simone) okay what was the issues with guitars, can

220 someone refresh my memory. Simone is just gonna play a bit of guitar while we talk

221 Aaron: and everyone wants to share...(is talking but conversation is drowned out by Simone

222 on guitar)

223 E: (other students indicate for Simone to stop playing the guitar, she gives it up, and Billy

Indicates that he wants it) yeah, okay. Karrie, Billy is just going to hold on the guitar for a

225 while whilst we have a bit of a chat (Aaron with hand up in the air).Yeah Aaron?

226 A: everyone should play a song that they like

227 E: yep, okay...so why is that important for everybody to do that?

228 J: Billy!

229 A: yep coz just don't want Simone playing high school musical, or mamma mia, or us playing

230

our rap, but Simone should play it just one if she likes that music for herself for

231

example

232 Karrie: I don't... A: no, Simone...in the bunny ears (not Karrie)

233 E: Oh okay...okay. so Simone likes the high school musical music..And Karrie too...and

234 Jackie...(as girls protest that Simone is not the only one there that likes that music)

235 Gavin: I like heavy metal 

pity.

237 (Aaron puts hand up) Yeah Aaron?

238 A: ah yes I like some heavy metal, but not all of it. E: okay G: and we've got a baby in the 239 house so it's not a good idea.

240 E: It's not the most soothing music for a baby to listen to while it goes to sleep is it? no...

241 (Jackie waving hand) yeah Jackie? (points to the floor, interrupted by Karrie)Karrie: I was on

242 the phone and was like 'hi (Jackie's' niece's name)', and she laughed!

243 E: ha-ha that's very cool. (Gavin and Aaron still talking in background) All right guys...so, are

244 you guys still talking about heavy metal?

245 Aaron: okay, let's talk about other things.

246 E: Ha-ha, okay...specifically can we talk about more of the group stuff that we did? (A: yup).

247 Okay, what did we think? What did we, any ideas remembering what we did? What was 248 some ideas of...

249 A: ar we played the guessing game with the instruments...

250 Yeah we did. What did you think of that game, Karrie? (K: good). Yeah? Cool. You didn't like

251 it Jackie? (Shakes head) why didn't you like it? (pause)

252 Billy: oh come on, come on stop being so slow! (laughter)

253 Jackie: Billy...Billy...(stares)

254 E: ooo, guys...Now, Jackie, is it okay to talk about what you didn't like about it? (Jackie

255 nods)what didn't you like about it? (Jackie is clicking fingers...looking around the

256 room...shaking hands, and verbalising...she is looking for something in the room)

257 K: loud music... (Jackie disagrees, shakes head)

258 Gavin: Jackie, use your machine

259 E: Oh, there were instruments that you didn't like?

260 G: drums...Jackie: Gavin...

261 E: What did it look like? It was long? What was it made of? Was it like a shaker? (J: no - 
visibly getting more agitated)

G: was it me? (laughter) E: no, it's not in the room now...

264 Aaron: I've got an idea (jumps out of frame). If people get out of hand they can use this drum just to stop them from getting out of hand

E: Oh...okay, so like using a drum to tell people to stop

Aaron: yeah, if they get out of hand. And whose job is it for a teacher... (gives it to

Brigette) (laughter)

E: very diplomatic, very diplomatic. Okay, Jackie, can you mime for me how to play the instrument that you are talking about (agrees)...so, guess what one Jackie's miming, all right? So it's like charades. (Jackie comes to me...whispers...I am trying to figure out what instrument she is talking about. In the meantime the students are playing up to the camera..Brigette uses the drum in a playful way to stop the behaviour)...

274 Gavin: use your computer (Jackie goes to get speech device)

275 (a lot of undistinguishable chatter in the background. Jackie and I are talking to try and 276 decide what instrument she is talking about)

E: We've got that it starts with an m...and it's not maraca (people are getting restless)

278 (conversation with the teacher aide..she figures it out to be the cow bell)

279 Brigette: is it the big one that I sometimes play? Jackie: no, Gavin. (makes triangulated shape with her hands)

281 Brigette : oh the cow bell.

282 J: yes!

283 E: Haha...okay. Did you hear what Jackie said? The instrument that she was talking about

284 with the game that she didn't like, was.. the cowbell..

285 Gavin: oh what?! That's the best thing about it J: (verbalises, waves arms wildly as if playing

286 loudly)

287 E: I think I understand, yeah..okay...so it can be less enjoyable depending on what

288 instrument you've got yeah? Okay. Allrighty, very very last chance to say anything about the 
289 group

290 G: can you put it up on TV (inaudible banter)

291 E: okay So, will just say thank you guys for taking part in it (everybody claps and hoots)

292 G: where's the wine, where's the wine! (chatter)

293 E: well to celebrate we'll do some games in music this afternoon.

294 (Rest of conversation about other music group-End of discussion group) 


\section{Appendix Three}

\section{Full Transcript Teacher Aide Interview}

1 E: Okay so we are Commencing interview with Brigette the teacher aide who's been helping

2 me with ah facilitating the music therapy group on Wednesday mornings

3 Okay. Hi Brigette

$4 \quad$ Hi Emma (laughter)

5 Thank you for taking part (laughter). Okay so what we're doing is um, this is gonna, this is

6 gonna take the format of like a semi-structured interview so there are a couple of questions

7 that l'll ask you but we'll just kinda of take it with (B: $\mathrm{mmm}$ ) whatever happens. Okay so just

8 to get out of the way we just had the focus group video(B: $\mathrm{mmm}$ ), and um.. when you were

9 sitting and watching the students listening to the recordings, did.. did you notice any

10 reactions that were slightly different to what you may have expected?

11 B: mmmm..no, but yeah something kind of was that they all thought that there was a

12 picture on, on the sound because they are so used to having a picture on the sound

13 (E: Yeah). That was very funny, they couldn't figure out where the picture was.(laughter)

14 E: Yeah so, well yeah, Billy saying ' oh but I can't see'

15 B: Yeah that was so funny!

16 E: You don't need to see, because I had specified that you know to listen (B: yeah, yeah) to

17 it, but I guess they associate the screen (B: with the sound?). Yeah.

18 B: Or maybe it's because they have the memory of the picture in their head because they 
19 are used to listening to music

20 E: That's true, that's true ..yeah. Um I thought it was interesting that after a while they all

21 started joining in with, with the rhythms. Like I mean Gavin kinda (B: oh yeah) did that (oh

22 oh yeah) dah dah dah dah (oh yes)

23 But I mean Simone was doing it,(yes, yes, yes) Simone was doing it and then kinda then

24 people where like 'oh okay, oh yeah alright' and so kinda remembering..coz they hadn't

25 been shown to go like that (indicates hand gestures)

26 B: No

27 To recreate the sound

28 B: I think it was amazing that he, Gavin, really remembered that

29 E: Yeah definitely so I think..

30 B: But he's very good. He's very good th the rhythms. (E: yeah) He's very, very good. $\mathrm{He}$

31 can start it anywhere (E:mm) on his own

32 E: He is very good (B: yes) and he's very solid kinda base with that. In saying that as well he

33 does that on to his own detriment too. He is so focused on what he's doing as an individual

34 (B: yeah, yes) that there could be another complete rhythm going but he'll say steady (B:

35 yes, yeah) but everybody else (B: yes) might change around him and he won't notice (B: no).

36 So that's, yeah quite, quite interesting. why do you think that might be?

37 B: Why he's going on, on his own? (E: $\mathrm{mm}$, yeah) I think that's something to do with the,

38 you know people either have the rhythm or not. Some can learn it, and some never learn

39 (laughter) but he has it in his body. I think that's why he can just go on. Er, yeah. 
40 E: yeah, I was trying to um when the video was running I was trying to pay attention to

41 what everyone was doing and I think that to kind of conclude with that they reacted the way

42 that I thought they would (B:mm) that I, you know um for example Gavin he's very dominant

43 person (B: yah) so he speaks him mind (B: yep) um...Andrew withdrew but he was, like,

44 when I reviewed the video material (yeah), he started grinning at some point coz I looked up

45 again and he was smiling (yeah). So I want to know what he reacted to

46 B: I think he is just sitting there and listening.(E: yeah) Yes

47 E: yeah. And whenever he does and you know, whenever you give instructions to

48 him, he's like straight away, he reacts (yep) and I think that was like, yeah, when..that's

49 what kinda I was alluding to when I was saying about what I liked about the group of people

50 helping each other out because the one person that really got help from the group was

51 Andrew

52 B: Yes

53 E: And I think from that perspective it was a really nice group like there were all very

54 different personalities in it but in that kind of banding together(B: yep) to help one

55 person (B:yep) which was really nice (B: yes).

56 E: Okay let's see. I've got some specific questions here. If we think about each student now,

57 how would you comment additionally on their interactions and responses in the video

58 session?

59 B: $m m m$.....Yeah I think maybe they weren't honest all of them but I think that it was very

60 good that Jackie she came through with her opinion and something that er I think I haven't 
61 been observing that before but that's because I yeah didn't think about it that they some of

62 them, actually and now...I, I should have known because I knew that before but I hadn't

63 thought about it in this group but some of them don't like high sounds, and that's a typical

64 thing for autistic children (E: yeah) and adults so that makes sense for me that some of

65 them didn't like the high sounds.

66 E: You do kinda think about also like adolescents for example with the volume with the too

67 loud drums, too loud. That's quite interesting for the tendency to turn up the music and

68 dance around and stuff (B: yeah) but in this kind of more intimate setting (B: yah) it's not

69 always the way they enjoy it the most (B: no). So I think it's quite, quite interesting that you

70 know always people are listening to the needs of others or you know like, stop it, it was

71 quite jokey but For them to say it could be improved with, with people playing at a quieter

72 volume (yes) is quite, um, well it's quite unexpected I guess

73 B: yeah I didn't even think about it at (E: yeah) all because I couldn't see them reacting on

74 their body language and they didn't say anything in all those lessons.

75 E: And you can't, you only have two eyes, (B: yes) you can't see everyone in the group (B:

76 no) there is so much going (B: yes) on there that

77 B: It has given me something to think about from this point in time....to do these, these

78 Things

79 E: I found with some students that I work with individually, I won't offer them certain kinds

80 of instruments, um with (child's name) I try not to, to like, singing too high (B: yeah), and um 
81 with certain kinds of instruments that really ring out like that tom drum I wouldn't use that,

82 because it's not necessarily the loudness of it, but the reverberation ( $B$ : yeah)and the

83 harmonics (B: yeah) that are about it (yes) that you can't hear, but that the kids can.

84 That cowbell is so horrid (yeah). If it's not played in the right way it can sound really really

85 bad (laughter)

86 E: Okay, um I just got another question here. What did you think of the compilation of

87 musical activities that we used in the sessions?

88 B: aah, I think the rhythm ones I really liked urr, and I could see for example Karrie improve

89 herself. She really did, because in the beginning she didn't know any rhythm at all. But she

90 really improved and I think that if maybe, if we continued one year from this would be

91 excellent playing rhythms

92 E: yeah, yeah

93 B: so that was really a moment from her mmm. I think some of them, because there is such

94 a big difference on the levels where they are, so some of them is enjoying just to play the

95 drum when it's...but for example urr, a person like Gavin or maybe Karrie and Aaron they

96 would, maybe have liked you playing songs on the guitar or learning a song on the guitar.

97 Some of the songs they know and they maybe have found out and play along with that and

98 but because of that, I know that because of the difference it may be maybe difficult to do

99 that (yeah) That kind of things and maybe some more place, of music and place and yes,

100 E: I think with more sessions we'd have more information and maybe students would 
101 be more um... willing to, to offer their own musical choices. Like they, um would kind of

102 like the idea of you creating a song or something like that (B: $\mathrm{mm})$. It's quite a personal

103 thing to say this is what I want to do and this is like in a group that you, you know (B:

$104 \mathrm{~mm}, \mathrm{~mm}$ ), we had three sessions and the group did not necessarily totally comfortable

105 of familiar one to say ooo lets sing this song in particular it's kinda easier to do an

106 activity, more ambiguous but with a personal song, and I hope that, one thing I really

107 tried to do in the group was give people enough options to say that that's what they

108 wanted to do. ( $B: \mathrm{mmm}$ ) Like coz the main aim of it was...it was improvisational group

109 music therapy (B: $\mathrm{mmm}$ ) and it doesn't always have to be like okay we are going to

110 think of an abstract theme and we are going to play on it, like the Rotorua exercise, um,

111 but even improvisation can go to people giving suggestions about what we are going to

112 do. So, yeah. I hope that it happens in other groups, and I think it does happen in the

113 bigger group (yes), not necessarily in this one. Yeah, which is really interesting. Yeah.

114 Okay, um....in your opinion did the music therapy sessions change the social atmosphere

115 in the classroom at any time?

116 B: mmm...yes...now I'm thinking also of the music lessons that we all have, the whole

117 class because eh, I really saw it different...they really change when they have the music

118 er lessons, they are very, And now l'm talking about the whole group (yep that's fine),

119 they really really pay some more attention and I can see that some of them...for

120 example Simone she's lighting up and you can see that she really is enjoying playing

121 music and Billy for example sometimes when we have math it's so difficult to get him,

122 his attention, but when he plays music he's really happy and...Yeah..

123 E: That's something that's happened very gradually well, from moving from the other

124 site, he, I had him originally as an individual client (B: yeah), and I stopped working with

125 him coz I couldn't. He just would not allow himself to, to be open to any suggestions, I 
126 was like (B: no...no, no) okay that's it I can't so will let him go. And going from that to him

127 actually verbalising and being a real active person in the music session that it's such a

128 huge difference in the space of time and, I mean that's individual goals in the group are

129 just as important as the group as a whole, yeah, he's expressing, like he's giving really

130 good like, when he would answer initially in the other group that he was in, would be a

131 lot of nonsense stuff and more a lot of teasing kind of. And that still comes through

132 often with him suggesting songs that we use, like how did we communicate...(B: yeah)

133 instruments...that was perfect, that was a really really nice thing to say (B: yeah) and

134 that's just such a huge difference from the first time that I saw him and it was really

135 unexpected to get that reaction from him

136 B: and that's nice

137 E: yeah

138 B: that's really nice

139 E: Meaningful moment in music therapy (laughs). Yeah it's great! It's been really really

140 good. Okay, um, so just a bit more here. How did you feel about taking part in the

141 course of music therapy sessions? And did it have any effect on your interactions with

142 students?

143 B: eeeh, yes I think that I have something special with the kids because of the music

144 lessons together and I think that it's nice to see them in another way that in this...math,

145 yes. And, and I feel that they really, eh, in the last end of the lessons that I was a part of

146 that group because today, when we went to go down they said "Brigette! You have to

147 come down" (laughs) so they knew that I was coming

148 E: oh very good. That's really really good. Was that the same with (the other teacher

149 aide) as well? Or was it just with you?

150 B: err, they didn't tell (the other teacher aide) 
151 E: ah when I talk about her I won't be referring to her name as (name), will just say

152 another teacher aide but I think she had a very different role from you anyway and she

153 was supporting the students, but we were in the groups in halves and yeah. I think that's

154 really neat that they were saying that. Yeah, because everybody's part of the team you

155 know. Like I've seen giving students music therapy just as important as giving teachers it

156 (B: yeah...yeah). coz I mean the group affects each other, no matter what role you play,

157 everybody effects each other (B: yes), it's really important. Okay. Ahh lets see. Are there

158 any differences in the sociability of the students of this particular class, and other classes

159 you may have noticed?

160 B: mmm no. I don't think so. Because they are very socialised anyway before this (E:

161 definitely), yes they are very, err, observant, (inaudible) and very kind. But something

162 that I really noticed and I am really impressed with the way they helped each other (E:

$163 \mathrm{mmm}$ ) in the school

164 E: it's really nice, isn't it

165 B: it is

166 E: it's a big goal (B: yes) of this unit of a community, kind of...

167 B: it is, but of course you have sometimes they get a little selfish but in the end they

168 are really nice students. Yeah.

169 E: cool. Okay, well that's the formal questions I have out of the way, so would you like

170 to talk about what you've got in your hand (laughter).

171 B: yes, because I didn't know exactly what you would expect from me (E: sure), and I've

172 only been with the group like four weeks and of course the other music lessons on the

173 whole class...so, I don't know if you can use this, but I know for sure that I, err, honest

174 what I think, and because I know how important that is (E: yeah) to your study (E:yeah

175 definitely) and I've written down is what I think is your strength (E: okay). Yeah err...

176 You're easy to understand in your verbal language as well as your body language and 
178 understanding of the children's needs, errr, and you are aware of their different levels.

179 That's also very important. And you are very patient (laughs) with them, which is even

180 more important. Err, it is obvious to me that you are enjoying the work. And, something

181 that I think is very special for you and that you're gonna, yeah, use in your job in the

182 future...I think you are very positive for new ideas er, even when it's from a trainee like

183 me (laughter). And that's very important skills to have, ah, yeah.

184 E: well, it's so...from my perspective, it's always important to have new ideas. It

185 doesn't matter what, what field it comes from, I mean the percussion ideas that you

186 Had...that was so good and I mean using it as an example today was, was fantastic and

187 that's part of being, you know part of this team and being receptive to other people's

188 ideas or else you just don't grow (B: no), you stay stagnant if you do your own thing(B:

189 yeah), so yeah, it's all about picking up on other people's stuff and getting new ideas

190 (laughs). Yeah.

191 B: I have some things that I think can be improved (E: okay), but I don't know and I may

192 be have some of the things..eee... I think that sometimes emm, it's nice to ask the, the

193 students what they want to think about, but maybe only in the beginning, and then you

194 take the decision after that because some of them, not all of them but some of them

195 really need structure (E: yeah), they can't cope with 'what do you think, what do you

196 want' (yeah). Is it okay ee, come with an idea..they can't do that always (E: okay). Em,

197 the, and what I said about lying down, eeh, that they must sit up because it's not easy

198 that when they are taught something, er, or if they have to play an instrument to lie

199 down, err, but I know that sometimes they think it's nice to lie down (E: yeah) and relax

200 that way, so maybe you could play some music in the end that tells them in the end I'm

201 going to play some music for five minutes (yeah), and you could lie down just to listen to

202 the music and relax (yeah). And then they will think 'ooo I'm allowed to do this" (E: 
204 E: okay, that's good.

205 B: um, yes. And there's also such a big difference between those, so what I said, some

206 more music and songs would help and, yeah, I don't know if it helps put them in smaller

207 groups, as they actually themselves notice that maybe you could make the group

208 smaller, or you could change them. And... then I think that also it's important to keep

209 William to share the guitar with other students, and I think that it's good that he found

210 that...to get away from him. (E: yeah) but he really needs to, because you could see how

211 happy Simone was to get the (E: I know!!) and that was her favourite thing. but They are

212 so nice that they don't err complain whenever William (yeah), he just grabs it and totally

213 into it.

214 E: yeah, I notice with the kids, in the other group and they were saying 'oh can we help

215 bring the instruments in" and I said 'that would be lovely, thank you so much for that'

216 that one of them would taking the instruments to help me, and the other ones would

217 be taking the instruments that they want (E: yeah), and it was the guitars, and I just, it

218 was just such a hard thing, and it ended up the same in the other class, and um, and

219 then my supervisor kinda said 'well, why don't you have a session when you have all

220 guitars' (yeah), like, okay, I need to find sixteen guitars (laughter)

221 B: that's a lot of guitars

222 E: yeah, that's a LOT of guitars so we will see how that goes

223 B: that's a brilliant idea.

224 E: yeah it would sound really interesting. Um, I've done sessions where it's been all

225 drumming, and that's been fantastic, like we had world music, and we had djembe

226 drums and it sounds soo cool (oh yes). I would love it if we could have some African

227 drums here

228 B: ooo yes. I love them 
229 E: and, um yeah, but it's just so, you've just got to learn that you can't always get what

230 you want and you have to be able to share with other kids - you know, it's not always

231 going to go your way (B: no), as hard as it is

232 B: it's hard

233 E: its hard to understand the concept of that

234 B: it is really. (laughter) and I want to say it has been a pleasure to be in the group

235 E: oh thank you

236 B: yeah, and I hope you can use my observations

237 E: Oh I definitely can, that's very good

238 B: and I wish you luck with your project

239 E: oh thank you. Well I hope that I've been able to, you know, that you will be able to

240 use some things that we have done as well (B: yeah I will), and, yeah, and it's just like,

241 honestly, just, it just worked out so well with having you part of the group and being

242 able for you to spend that extra time with Helen, and to have another perspective

243 on somebody that is quite open to the idea of music therapy and actually, just signing

244 the paper and saying yes, it was just the biggest relief, coz nobody...everybody wanted to

245 take part, but nobody wanted to take responsibility for it and it's not, it's not the most

246 time consuming thing, or it's not too scary having your name on a piece of paper and

247 your fake name in a book (laughter), so, yeah I hope that, that it's been enjoyable and

248 the kids have obviously really enjoyed having you as part of the team as well (yes), so

249 thank you for everything, thank you for your time

250 B: you're welcome.

251 E: it's been great. Cool. 


\section{Appendix 4}

\section{Full Transcript Teacher Interview}

1 Emma: Hi (Teachers name)

2 Teacher: $\mathrm{Hi}$

3 E: So, did you just get a chance to look at the video and the transcript?

$4 \quad$ T: I did

5 E: You did. Okay. Um, would you mind answering a couple of questions?

6 T: Certainly

7 E: Thank you. Okay... Could you comment on the students' reactions to listening to

8 the music in the focused - videoed group? Um, were there any specific things

9 that stood out for you?

10 T: um, they're all... They all appeared to be focused and um listening to it. Um, then

11 you've got a lot of them repeating the rhythms that were being played in the songs,

12 um, Gavin especially started it, um...Simone even tried, tried to chime in and Billy as

13 well. So, no they're all fairly engaged.

14 E: okay. So that listening to that song was, that was something that stood out for

15 you, them mimicking that song?

16 T: yes.

17 E: okay, right. Um, okay. If you think about each student now, how would you

18 comment additionally on the interactions and the responses in the videoed session?

19 T: um, in re... fairly, they're fairly standard; I mean they were very, very engaged,

20 and very, um enthusiastic about, about being involved in it. Um, probably even a

21 little bit more than they would be in class. Um... 
22 E: why do you think that might be?

23 T: um... Slightly informal? Um, and its fun. They all, a lot of them, all of them like,

24 like music, um, they like discussing it. Um, and they're in a, a small group of people

25 they are comfortable, well, students that they are comfortable with.

26 E: okay. Um, what do you think of the compilation of music activities that we used in

27 the session?

28 T: so, as in?

29 E: as in listening to the um, there was the hand clapping

30 T: yip

31 E: that the kids got to listen to. (T: $\mathrm{mhmm}$ ) What did you think of that, what did you

32 think of that as an activity that the kids took part in?

33 T: it was, no it was good, it, it was a good activity. They, um, they got the co-

34 ordination and um interaction going well and by the sounds of things there were two

35 groups, one doing one rhythm and one doing another, um which can be quite

36 difficult to co-ordinate

37 E: okay, um alright onto the next question. Um, In your opinion did the music

38 therapy sessions change the social atmosphere in the classroom at any time? And if

39 so, what were the changes?

$40 \mathrm{~T}$ : um, they were a little bit more enthusiastic, um, and, and, and engaged in the

41 activities than maybe they would be in class, um because they obviously enjoy their

42 music sessions they have with you, um in class they may not be enjoying what

43 they're doing, um...So the atmosphere would be um a bit more engaging and um, a

44 bit less...Little bit more light hearted. 
45 E: um, finally l'll just ask um are there any differences in the sociability of the

46 students of this particular class and the other classes that you may have noticed?

47 T: um, Billy I noticed was a little bit more engaged than he would be in class

48 normally, um he can have a tendency to withdraw and not be involved, um decide to

49 do his own thing, but through that session he was pretty much engaged- he did a

50 little bit of niggling with other students, but he almost stopped himself from doing

51 that, um and re-engaged back into the group.

52 E: Why do you think that might have...Why do you think he did that?

53 T: um...different setting maybe? Um smaller group, there's more things for him to

54 re-engage back into, um, yeah. Not $100 \%$ sure of why he stopped himself from

55 distracting other students, which is something I've never really noticed with him

56 before.mm (E: mm!) Um, Simone was, was focused for Simone as well. She um,

57 asked appropriate questions or responded appropriately as opposed to some

58 tangential um comment that she quite often pops out in class.

59 E: yeah. Um, what about Andrew?

60 T: Andrew, that's pretty much the standard um responses from him, he will only

61 respond to you if you engage with him. Um, He won't, won't be spontaneous or um,

62 off his own back respond or comment. That's not to say he wasn't paying attention

63 or listening, um quite, he probably quite was, I mean he's in to his music. He's

64 probably just sitting there, listening, um but unable to respond.

65 E: so, would you say engaged but not responding?

66 T: yeah

67 E: and, um any of the other students that you would like to comment on?

$68 \mathrm{~T}$ : um, no all, all the other students pretty much displayed what they were like in the 
69 classroom really. Aaron was a little bit more forthright, a little bit more um

70 confident, um in class, ah sorry in your session. And I think in um class he would

71 respond to questions a lot quicker, um and he'd ask question or things like that.

72 Mmm Gavin was pretty much his typical self, um, the same as Jackie and Karrie

73 really. Karrie was actually a little bit quieter, a little bit more focused even quite, she

74 can be quite distracted at times, but no she was quite focused in that. Yeah.

75 E: Alright. Yeah, um, anything else you would like to add?

76 T: Aaaah, um no, don't think so...

77 E: okay, thank you. 


\section{Appendix 5}

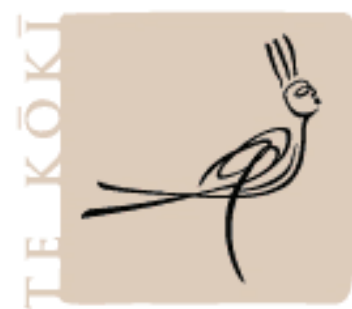

NEW Z EALAND

SCHOOL:MUSIC

\section{INFORMATION SHEET FOR CHILDREN}

Hello there class. I am going to be doing a study and I invite you to take part in it.

I am asking your teacher to read this letter so that he can tell you about my study. I am going to write a short book about the time that we spend together in music on Tuesdays. This book will be published next year and will be available for people to read from the Massey library.

The book will be about the songs that we create in our music therapy sessions, and what we think about them.

So that I have material to write about for my book I will be recording our music therapy sessions on my MP3 player and listening to them after we finish our session. Later on in the year I might ask you to listen to them in a small group for up to an hour. I will video record this group so that I can write down what we said about our songs and what we think about our music. When the group has finished, I will talk to a teacher aide about what they thought about the music and the sessions that we have. After that is all done, I will watch the video and write notes about it. I will also be writing down everything that is said in the group so that I have a typed up copy that I can include in the book.

If you don't want to take part in the study, that is okay. You will still be able to come to our music therapy sessions and play songs. If you do want to take part you will need to sign the forms titled 'Student Consent Form' and return it to your teacher. Your parents have also been given a copy of this letter if you need help making your decision. Also if you are younger than 18 years old you will also need permission from your parents to take part. If you are taking part in the study you will be told in advance when the small group will be taking place.

You will be assigned a pseudonym, which means your real name won't be used in the book. I will try my very best to make sure that people reading the book won't be able to guess who is taking part.

You can ask me any questions you want to about the study. If you change your mind about taking part in the study, that is okay too.

Thank you very much, have a great day

Emma. 
Appendix 6

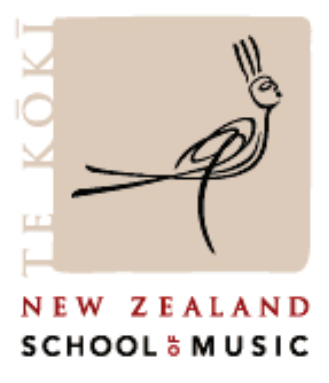

\section{Promoting Sociability: Staff and Student Perceptions of Music Therapy in the Classroom (former project title).}

\section{STUDENT CONSENT FORM}

This consent form will be held for a period of five (5) years

I have read the Information Sheet and have had the details of the study explained to me. My questions have been answered to my satisfaction, and I understand that I may ask further questions at any time.

I agree to participate in this study under the conditions set out in the Information Sheet.

Signature:

Date:

Full Name - printed 


\section{Appendix 7}

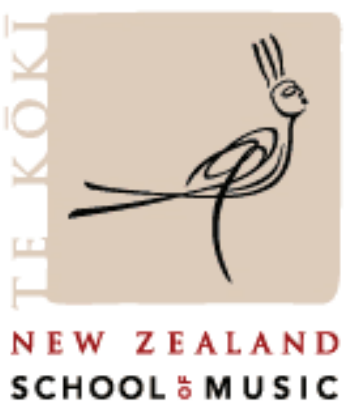

\section{Promoting Sociability: Staff and Student Perceptions of Music Therapy in the Classroom. (former project title)}

\section{INFORMATION SHEET FOR TEACHER AIDE}

A project conducted by Emma Boniface as part of the Master of Music Therapy Programme.

Contact: misseboniface@gmail.com, 021-1876-385

Supervisor: Sarah Hoskyns, Director of the Master of Music Therapy Programme, New Zealand School of Music.

Contact: sarah.hoskyns@nzsm.ac.nz, 8015799x6410

\section{INTRODUCTION}

You are invited to take part in a research project about music therapy and the classroom. This project aims to look at the ways students take part in the group activities in music therapy sessions at school. I am running this research project as part of the Master of Music Therapy programme at the New Zealand School of Music. I am interested in looking at the way the students socialise together in the classroom, and how they work together as a group. This invitation gives you the opportunity to take part in a videoed focus group with our students, and then to review this video and to take part in an interview with myself about the students interactions within the group. In previous studies on special education and Music Therapy (MT), MT can be an outlet for students both emotionally and physically. Just some of the skills that are used in MT are co-ordination, listening skills, turn taking, reasoning skills, muscle movement, and social interaction. MT can be complimentary to the goals that have been set for students at their school and works in close proximity with the aims of the education provider.

\section{CRITERIA FOR PARTICIPATION}

For this study I would ideally like to recruit one teacher aide who has taken part regularly in group music therapy sessions in the past few months. If another teacher aide that would also like to take part in the study then they will be accommodated. The class teacher will invite you and answer any questions about the project that you may have. You will have two weeks to decide if you would like to take part. There is no obligation to participate. You will still be welcome to take part in the music therapy sessions as usual. 


\section{WHAT WILL PARTICIPATION IN THIS RESEARCH INVOLVE?}

I would like to include a teacher aide's perceptions about children's responses in music therapy in this study. As a colleague who has taken regular part in the sessions, you will be invited to join a "focus group" with several students from our MT sessions and yourself to reflect upon some recorded songs that we have created in music together. This focus group will be video recorded so that we can look at physical reactions to the music, as well as think about what the students say. The focus group will meet only once, and will convene for a maximum of one hour. After the session has finished, I will invite you to review the video and take part in an interview about the focus group. This will go for no longer than an hour in duration and will take place at your convenience on school premises.

Information about the participants in this study will remain confidential to the researcher and the participants. The data will be kept by myself, and will only be discussed with my supervisor, Sarah Hoskyns. Due to the small number of music therapy students and practitioners working in New Zealand, it may be possible that the school could be recognised by readers of the published work, but I will try my utmost to protect the identity of participants in my writing. The final project will not include the real names of the participants and the location of the school will not be identified. After the completion of the research, the data will be stored securely at the New Zealand School of Music for a period of five years, after which it will be destroyed.

If you accept this invitation to take part in the research, please fill out and return the attached consent form.

You and are under no obligation to accept this invitation. If you decide to participate, you have the right to:

- decline to answer any particular question

- withdraw from the study at any time up to verification of the interview transcript

- ask any questions about the study at any time during participation

- Be given access to a summary of the project findings when it is concluded.

- Receive a transcript of the interview for correction and verification.

.If you have any questions about the project, please feel free to contact Emma Boniface and/or her supervisor, Sarah Hoskyns.

This project has been reviewed and approved by the Massey University Human Ethics Committee: Southern A, Application 08/27. If you have any concerns about the conduct of this research, please contact Professor John O'Neill, Chair, Massey University Human Ethics Committee: Southern A, telephone 063505799 x 8771, email humanethicsoutha@massey.ac.nz

\section{Appendix 8}




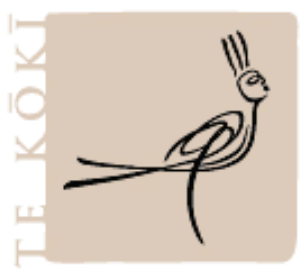

N E W Z E A A N D

SCHOOL

\title{
Promoting Sociability: Staff and Student Perceptions of Music Therapy in the Classroom. (former project title) TEACHER AIDE PARTICIPANT CONSENT FORM
}

\begin{abstract}
This consent form will be held for a period of five (5) years
I have read the Information Sheet and have had the details of the study explained to me. My questions have been answered to my satisfaction, and I understand that I may ask further questions at any time. I understand that I can decline to answer any questions and that I can ask for the audio recording device to be switched off at any time. I understand that I will receive a transcript of my interview for correction and verification. I understand that I can withdraw from the research at any time, up to the verification of the transcripts. I understand that information that I give in the interview will remain confidential to the researcher and the supervisor and that my real name will not be used in the thesis. I understand that for the purpose or this research that the interview will be audio taped, and the focus group will be videotaped.
\end{abstract}

I agree to not disclose anything discussed in the Focus Group

YES

NO

I agree to participate in this study under the conditions set out in the Information Sheet.

Signature:

Date:

Full Name - printed

Appendix 9 


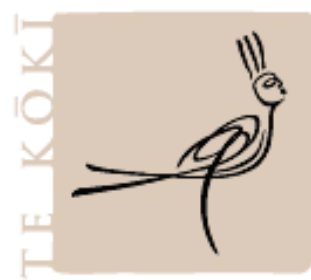

NEW Z E ALAND

SCHOOL: MUSIC

\section{Promoting Sociability: Staff and Student Perceptions of Music Therapy in the Classroom. (former project title) PARENT CONSENT FORM}

This consent form will be held for a period of five (5) years

I have read the Information Sheet and have had the details of the study explained to me. My questions have been answered to my satisfaction, and I understand that I may ask further questions at any time.

I (please print full name) agree for my child (please print full name) to participate

in this study under the conditions explained in the information sheet.

Signature:

Date:

Full Name - printed 